\title{
A Practical Guide for Implementing the STEM Assessment Results in Classrooms: Using Strength Based Reports and Real Engagement in Active Problem Solving (REAPS)
}

\author{
Randy Pease, B.A., Mary Vuke, M.S., C. June Maker, PhD., Litt. D. \\ The University of Arizona \\ Omar M. Muammar, Ph.D. \\ Imam Abdulrahman Bin Faisal University, Dammam, Saudi Arabia
}

Pease, R. Vuke, M.H., Maker, C. J., \& Muammar, O.M. (2019). A practical guide for implementing the STEM assessment results in classrooms: Using strength-based reports and real engagement in active problem solving (REAPS). Journal of Advanced Academics. 31(3) 367-406. DOI: 10.1177/1932202X20911643

Author Note

Randy Pease, Teacher Educator, Department of Disability and Psychoeducational

Studies, University of Arizona, Tucson, AZ.

Correspondence concerning this manuscript should be addressed to Randy Pease,

Department of Disability and Psychoeducational Studies, University of Arizona. E-mail:

pease_schoolstuff@hotmail.com

This research was supported by the National Science Foundation, Grant \#1321190,

Cultivating Diverse Talent in STEM; PI, Uwe Hilgert; Co-PIs C. June Maker, Frans Tax, and Martha Lindsey, University of Arizona; Harold Begay, Tuba City Public Schools. 


\begin{abstract}
Developing students' strengths while teaching the content required by national and state standards in science, technology, engineering, and math is challenging for classroom teachers. In the Cultivating Diverse Talent in STEM (CDTIS) Project, the assessment results found in strength-based reports gave teachers the tools needed to pursue STEM projects that were community and globally inspired, student selected, and aligned with standards. Results of Discovering Intellectual Strengths and Capabilities while Observing Varied Ethnic Responses (DISCOVER) assessments were compiled into easy-to-understand charts and profiles for each student and the class as a whole; the data from assessments of creative problem solving in all domains were combined to show the students' strengths. Profiles were then given to students and their parents. Reports contained a summary of the assessments, ideas for developing each area of strength, useful materials, ways to move from focusing on "right answers" to rewarding creative thinking, and careers aligned with the domains of ability. Teachers and students participated in Real Engagement in Active Problem Solving (REAPS) in which students solved real-world problems from their local communities and the world that were connected to their academic areas of study. Using REAPS in any STEM area boosts students' focus, motivation, interest, and understanding.
\end{abstract}

Keywords: REAPS, STEM, strength profiles, problem solving, assessment results, diversity, gifted, teaching high school students, talent development, teaching 
Cultivating Diverse Talent in Science, Technology, Engineering, and Mathematics (CDTIS) was a project addressing the National Science Foundation (NSF) priorities. The purpose of the project was to increase the number and diversity of exceptionally talented students so they could have access to interventions that would increase their learning and help them develop toward becoming Science, Technology, Engineering, and Mathematics, (STEM) innovators who could create "significant breakthroughs or advances in scientific and technological understanding" (National Science Board, 2010, vii). In the CDTIS Project, new assessments were created for life science and mechanical-technical abilities, including both performance-based and paper-and-pencil measures using the Discovering Intellectual Strengths and Capabilities while Observing Varied Ethnic Responses (DISCOVER) model (Maker 2005). In addition, the math assessment was revised to include more geometry concepts and an existing assessment of spatial analytical ability was incorporated into the group of instruments used to select students for special opportunities offered during the project. The final battery of assessments included six components: Math, Life Science Concept Mapping, Physical Science Concept Mapping, Life Science performance assessment, Mechanical-Technical performance assessment, and Spatial Analytical performance assessment. All were measures of knowledge, application of knowledge, and creative use of knowledge. Important to note is that performance assessments included components not often found in multiple-choice tests, such as observation by an expert while completing semi-open and open-ended tasks requiring higher order thinking and problem solving (Maker, 2019; VanTassel-Baska, 2014). In these assessments, correct use of English, both in writing and speaking, was not required. Students' abilities were assessed directly through the tools and symbol systems of each domain by evaluating the students' original 
products (e.g., spatial, life science, physical science) in a debriefing setting rather than indirectly through the lens of language. Thus, these assessments can be used to identify exceptionally talented students who have not been identified using conventional methods (Sarouphim \& Maker, 2010; Maker, 2019; Wu, Pease, \& Maker, 2019).

The assessments developed through this project include methods to recognize students who can identify problems, design their own methods, and create new solutions rather than simply replicating experiments with known outcomes, remembering facts, or implementing others' solutions (Brandwein, 1992; 1995; Matsuko \&Thomas, 2014). In his studies of the predictive validity of various methods, Wallach (1976) demonstrated that past performance in a domain predicts future performance in that domain: tests predict test scores and performance predicts performance. In the project, students were given the opportunity to participate in research in the laboratories of scientists at an R1 University in the Southwest. Laboratory experiences included both problem-doing and problem-solving (Brandwein). Problem-doing experiences are planned laboratory experiments, with established outcomes, while problemsolving experiences are those in which students are allowed to identify their own problems and design experiments to solve these problems (Brandwein). The programs and curricula provided in partner schools were aligned with assessments after the internship experience to develop exceptional talent in STEM based on prior research with the DISCOVER curriculum model and Real Engagement in Active Problem Solving (REAPS).

The purpose of this article is to assist teachers in aligning programs and curricula with student talents so they can develop their students' strengths, and to provide readers with a practical and research-based tool box they can use to incorporate a continuum of problems, differentiate curricula, and use teaching strategies that contribute to the development of students' 
talent and creativity in STEM. In the first section, we describe curriculum modifications for exceptionally talented students using the DISCOVER curriculum model (Maker, 2005; Maker, Muammar, \& Jo, 2008; Maker, \& Schiever, 2010) and relate those modifications to each ability evaluated during the assessments. The second section contains a description of the REAPS model, a teaching model designed to meet the needs of all students (Maker \& Zimmerman, 2008; Wu, Pease, \& Maker, 2015) but especially appropriate for developing problem solving abilities of exceptionally talented students (Maker, Zimmerman, Alhusaini, \& Pease, 2015b). The REAPS model includes the DISCOVER model and evolved because of the need to incorporate additional components to enable teachers to develop students' abilities more effectively (Reinoso, 2011). An example of a successful REAPS unit is included.

\section{Best Practices in Education of the Gifted}

According to the National Association for the Gifted (NAGC, 2010), important student outcomes are the following:

- Students with gifts and talents demonstrate growth commensurate with aptitude during the school year (3.1).

- Students with gifts and talents become more competent in multiple talent areas and across dimensions of learning (3.2).

- Students with gifts and talents develop their abilities in their domain of talent and/or interest (3.3).

- Students with gifts and talents become independent investigators (3.4).

- Students with gifts and talents develop knowledge and skills for living and being productive in a multicultural, diverse, and global society (3.5). 
- Students with gifts and talents benefit from gifted education programming that provides a variety of high-quality resources and materials (3.6).

To accomplish these outcomes, certain "best practices" are recommended for each student outcome. For example, to accomplish the first outcome, educators are encouraged to (a) use local, state, and national standards to align and expand curriculum and instruction; (b) use a comprehensive and continuous scope and sequence as a framework; (c) adapt, modify, or replace the core curriculum; (d) incorporate advanced, conceptually challenging, in-depth, complex content; (e) use pre- assessment to determine current knowledge and skills; (f) pace instruction based on the students' learning rates; and (g) incorporate technology (NAGC, 2010).

To accomplish the second outcome, best practices include (a) designing curricula to address cognitive, affective, aesthetic, social, and leadership needs and (b) using metacognitive models; while accomplishing the third outcome, best practices include (a) selecting, adapting and using varied methods and materials; (b) using school and community resources; and (c) providing opportunities for students to explore, develop, or research their areas of interest and talent. The fourth outcome is accomplished through using (a) critical thinking strategies, (b) creative thinking strategies, (c) problem solving strategies, and (d) inquiry. For the fifth outcome, educators are encouraged to (a) develop and use culturally responsive curricula and (b) integrate career exploration into learning opportunities. Finally, to accomplish outcome six, the best practice is to become familiar with high quality resources and materials that can be used with learners who have gifts and talents (NAGC, 2010).

\section{Curriculum Modifications for Exceptionally Talented Students in STEM}

Curriculum models for exceptionally talented students include several modifications for effective STEM classrooms. Content, process, product, and learning environment modifications 
are characterized by (a) integrated, interdisciplinary content (Feng, VanTassl-Baska, Maker \& Schiever, 2010; Quek, Bai, \& O’Neill, 2005; Johnson, 2011; VanTassel-Baska \& Little, 2011; VanTassel-Baska \& Wood, 2010); (b) higher-order thinking skills (Hunsaker, 2005; Maker \& Schiever, 2010; McAllister \& Plourde, 2008; McCluskey, Baker, \& McCluskey, 2005), (c) development of unique products for real audiences (Chamberlin, 2010; Hockett, 2009; Maker \& Schiever, 2010); and (d) student interaction, interaction with experts, and flexible, open learning environments (Hockett, 2009; Maker, Alhusaini, Zimmerman, Pease, Schiever, \& Whitford, 2014; Maker \& Schiever, 2010). Content should be abstract and complex; including a variety of topics, organized around key concepts, include study of people and study of methods in various fields. Process modifications include higher level thought, open-endedness, discovery learning, evidence of reasoning, freedom of choice, group interaction, pacing, and variety. Product modifications include real problems and audiences (Hockett, 2009), transformations, variety, self-selected formats, and appropriate evaluation (Cheng, Lam, \& Chan, 2008; Maker, et al., 2014; Maker \& Schiever, 2010; Perrone, et al., 2010). Learning environments should be studentcentered (Hockett, 2009). The teacher serves as a guide for students who have opportunities to make choices based on their interests and abilities. Teachers encourage creativity by accepting students' ideas rather than judging them (Mann, 2006). The teacher, in an open-ended learning environment, encourages students to share their thinking and allows them to become autonomous learners (Hockett, 2009; Maker \& Schiever, 2010). When presenting an open-ended question or statement, wait time is essential to encourage deeper, more meaningful, and creative thinking (Kelly, 2020; Rowe, 1972). Independence also is encouraged through student choices of products, interactions with peers, and, when appropriate, choice of content and activities 
(Hockett, 2009; Maker \& King, 1996; Maker \& Nielson, 1995; Maker, Rogers, \& Nielson, 1996; Maker, et al., 2014; Maker \& Schiever, 2010; Wu, et al., 2019).

When students know their strengths they can learn prescribed skills, concepts, and curriculum standards more efficiently; and can make effective choices. Use of assessments in the classroom is based on the belief that students learn most efficiently and effectively by using their strengths to develop academic and real-life skills (Maker \& Pease, in press). Students gain confidence in their abilities as they experience success in learning new material. They perceive the strengths of other students and gain respect for their classmates (Hiemstra \& Van Yperen, 2015). Students need time to understand their unique patterns of abilities and through choice can develop an appreciation for what they are good at doing. When these strengths are used to study real-world problems, academic skills take on new meaning and relevance. Students develop more positive and realistic beliefs about their own abilities and how they can use those abilities to succeed (Maker, et al., 2014; Maker \& Schiever, 2010).

Effective teachers provide opportunities for students to develop their multiple abilities using active hands-on learning with the "tools" and symbol systems of the multiple abilities. Curricula are planned around state standards and abstract themes. Teachers integrate the culture of the students and of the community into the curriculum. Lessons include direct instruction, guided practice, hands-on problem solving, and a continuum of problems ranging from wellstructured to open-ended problems. Teachers guide students in constructing their own learning from highly structured experiences to open-ended experiences, making significant choices about their own learning, and having access to a wide variety of materials (Maker, 2005). The DISCOVER curriculum model has been shown to contribute significantly to the development of students’ creativity (Maker, Muammar, Serino, Kuang, Mohamed, \& Sak, 2006; Maker, et al., 
2008). In addition, research in a school in a low income area with significant percentages of culturally diverse students in which the DISCOVER model was used in all classrooms showed that student achievement increased from an average of 18 th percentile to an average of $62 \mathrm{nd}$ percentile over a four-year period (Figure 1) (Maker, 2004). In another school, science scores of students in classrooms of high implementer teachers were significantly higher than the scores of students in classrooms of low implementer teachers (Figure 2) (Maker, 2004).

\section{Problem Continuum}

A key component in a classroom for exceptionally talented students is the problem continuum developed by Maker and Schiever (2010). When developing plans, teachers design lessons that include a variety of types of problems. Real-life problems include both wellstructured problems, such as gaining background knowledge or how to conduct field tests, and open-ended problems, such as creating solutions or communicating those solutions to stakeholders (Alhusaini \& Maker, 2011). Student engagement increases as students struggle with real-life issues, learning content and skills as well as critical thinking (Riley, Webber, \& Sylva, 2017; Webber, Riley, Sylva, \& Scobie-Jennings, 2018). Because the problem continuum includes a variety of problem types, both structured and ill-defined or unstructured, students are guided through a process of moving from familiar academic-type problem solving (a clearly stated problem with a right answer and specified methods) to the less familiar problem solving in which they can propose an infinite number of solutions and choose a method they believe is appropriate. The least structured type of problem students experience is 'problem finding' as they define for themselves the problems they will find and solve (Alhusaini \& Maker, 2011; Gallagher, 1997; Maker, et al., 2008).

\section{Curriculum differentiation}


Curriculum differentiation (Tomlinson, 2013) is used to develop activities to address all students' intellectual needs. In literature describing appropriate engagement for exceptional learners, the general consensus of experts and researchers is that students will become engaged and excited learners who are challenged by the complexity and authenticity of what they are learning and producing. These principles are based on, built on, and extend the characteristics of the exceptional learner (Gubbins, 2013; Kaplan, 2009; Maker, 1982; Maker \& Schiever, 1996; Maker \& Schiever, 2010; Renzulli \& Reis-Renzulli, 2010; Tomlinson, 2013; VanTassel-Baska \& Brown, 2007). Teachers provide differentiated resources, activities, and products for individual(s) or small groups of students who have similar intellectual strengths to learn content and share information $(\mathrm{Wu}, 2013)$. Using assessment results, teachers design learning experiences to develop students' area(s) of strength. For example, students who have a strength in mathematical ability interpret information from tables, charts, and diagrams to learn new content. Students with mechanical-technical strengths could work on a product such as modelbuilding and 3-D design. Students who possess spatial analytical and mathematical strengths can work on a product such as a diagram, a geometric characteristics table, flow chart, or puzzle. Teachers need to determine what types of intellectual strengths are in the classroom, and then think about sources of information or products that represent each type (Levy, 2008; Maker, Alhusaini, Pease, Zimmerman, \& Alamiri, 2015a).

\section{Teaching Strategies for Abilities}

The assessments developed through this project were designed to identify student strengths in several domains: mathematical, spatial analytical, life science, and physical science. The following discussions of each domain provide educators with ideas for modifications of the content, process, product, and learning environment to encourage learning with each ability 
(Maker, \& Schiever, 2010; Renzulli \& Renzulli, 2010). During the CDTIS project, a report describing each student's abilities with suggested ways to develop the abilities through modification of content, processes, products, and the learning environment was given to teachers. A short report with ideas for developing the abilities was given to parents and students after assessments were completed (Maker, Zimmerman, Pease, \& Jo, 2014).

\section{Developing Mathematical Ability}

Students who possess mathematical ability can analyze problems logically; understand the underlying principles of systems; calculate and manipulate numbers, quantities and operations; solve complex mathematical problems; use experiments to test solutions; and explore patterns and relationships (Gardner, 1983; Maker \& Anuruthwong, 2013). These abilities are used by engineers, lawyers, accountants, real estate agents, financial planners, statisticians, math teachers, and others who work with numbers and who attempt to predict or plan for the future.

Creative applications in mathematics are required for the exploration of problems and problem solving (Mann 2006). He states that "Teaching mathematics without providing for creativity denies all students, especially exceptionally talented students, the opportunity to appreciate the beauty of mathematics and fails to provide the gifted student an opportunity to fully develop his or her talents." (p. 236). Creativity and problem-solving are necessary components of content for gifted learners (Maker \& Schiever 2010). Content that includes a focus on discipline-specific skills and concepts, and the inclusion of content experts also are essential components of content development (VanTassel-Baska \& Little, 2011).

Content modifications for students with strength in mathematical ability include teaching abstract concepts such as number systems, patterns, structure, and change. Relating math and science concepts to real-life situations deepens students' understanding of the content and helps 
them see the relevance of what they are learning (Mann, 2006). Teaching basic math from concrete to abstract, including calculation, pattern awareness, and quantification, provides students with the skills needed to solve complex mathematical problems (Johnson, 2011; Liekin, 2010). Students' organizational skills are developed by learning classification and categorization systems. Observing scientific demonstrations and participating in student-designed experiments allow students to learn and practice scientific methods (Chamberlin, 2010). Interacting with professionals from mathematical fields provides students with examples of the ways mathematical abilities are used in the world beyond school.

Process modifications include Socratic questioning, teaching heuristics, and practicing scientific thinking (Cai \& Lester, 2010; Howley, Pendarvis, \& Gholson, 2005). The mathematical abilities of students are enhanced by asking them for reasons and evidence for their thinking. Authentic applications such as travel, shopping, and cooking give students practice planning for the future. Participating in discussions of individual and group interpretations of problem-solving processes (Gavin \& Adelson, 2014; Gavin, Casa, Adelson, Carroll, \& Sheffield, 2009) allows students to better understand their own ability. To encourage high level thinking, questions are open-ended to encourage students to provide evidence of their reasoning. Teachers can create activities to develop mathematical skills over time such as mock companies and communities. Using computers as tools and learning computer programming encourages complex thought processes.

Product modifications that often appeal to students with mathematical abilities include Venn diagrams and matrices, timelines, outlines, tables, and charts. Students can create codes, computer programs, classification systems, patterns, logic puzzles, and games. Students selfselect a product to share their learning with real audiences. 
Learning environment modifications for mathematical abilities include displays of formulas, tables and graphs, timelines, diagrams of relationships and/or systems, Venn diagrams, and matrices. The environment should be rich with hands-on materials, games, calculators, cooperative learning games, and various sources of information. Students are encouraged to practice these skills when activities are fun, relevant, and challenging (Chamberlin, 2010; Johnson, 2011; Leikin, 2010; Maker \& Schiever, 2010).

\section{Developing Spatial Analytical Ability}

Spatial Analytical abilities include perceiving the visual world accurately through keen observation, producing a graphic likeness of spatial information, seeing images clearly in one's mind, producing transformations and modifications in a visual or other form, recreating or interpreting aspects of one's visual experience, and sharing information learned through a visual product (Gardner, 1983; Maker \& Anuruthwong, 2013). These abilities are used by engineers, astronomers, architects, mathematicians, builders, city planners, and others who need to be able to see the big picture and fit all the parts together to make something work.

Content modifications for students with spatial analytical ability include teaching macro concepts such as systems, patterns, structures, and symbolism through various content areas. All content can be enhanced by using graphic and visual organizers, incorporating charts, diagrams, 3-D models, and other similar methods to analyze and learn new content. Students are reminded to use these abilities when teachers use concept maps, diagrams, models, and words such as imagine, picture, and visualize during instruction. Teachers can use illustrations, sketches, drawings, active visualizations, and imagination to make content more available to students with spatial analytical strengths. 
Process modifications for students with spatial analytical ability include giving them time for constructing, assembling, designing, and sculpting to deepen understanding of content. Students with this ability learn content efficiently through idea sketching, graphic symbols, color markers and/or coding to represent different ideas. Teachers and students can use overhead transparencies, whiteboards, graphic organizers, and smart boards during instruction or study time.

Product modifications for students with spatial analytical abilities include using sketches, making graphic organizers, and building 3-D models for sharing information (Hsu, Lin, Lee, \& Hwang, 2012). Written information can be enhanced by illustrations. Students need a variety of materials such as cameras, video recorders, props, junk art supplies, and similar materials for relating information to others. Students can self-select formats for products or design their own products using unique combinations of formats.

Learning environment modifications for students with spatial analytical abilities are graphic-rich with color coding systems, brightly colored pictures, charts, organizers, and models. These students need a variety of materials to explore new learning and share new insights with others. They also need time for creative exploration of a variety of hands-on materials to illustrate concepts, relationships, vocabulary words, and experiences (Maker, et al., 2014; Maker \& Schiever, 2010).

\section{Developing Life Science Ability}

Students who excel in life science ability explore and care for their environment, categorize and catalog information easily, observe details and behaviors in nature, discern relationships within a habitat, and perceive changes in the environment (Gardner, 1999; Maker \& Anuruthwong, 2013). Biologists, conservationists, farmers, medical professionals, park rangers, 
and others who show a concern for the environment, understand interrelationships, and can explain natural phenomena have strengths and interests in life science.

Content modifications for students with life science ability include teaching concepts such as ecosystems, interrelationships, interdependence, and habitats. Students learn information through taxonomy keys for classification and categorization, and teachers can give students examples to enable them to create their own classification systems. Students develop deeper understanding of relationships within a habitat by creating and presenting models of ecosystems and food chains (Hsu, et al., 2012; Maker, 2013; Tai \& Miedjinksy, 2005). Students need to interact with local experts such as biologists, medical professionals, forest rangers, and others through classroom talks or field work (Tai \& Miedijensky, 2005).

Process modifications for students with life science strengths center on observation of natural environments. Field studies to natural areas and natural history museums provide information and opportunities to collect specimens. Students need time to observe changes and interactions in natural areas or between natural elements. Participating in whole class discussions of problems related to biological classification, global warming, pollution, and other controversial subjects benefits all students (Hsu, et al., 2012). Students need to engage in challenging tasks involving ecosystems such as designing ways to reduce or delay climate changes (Jo \& Ku, 2011).

Product modifications for students with these abilities include collections of local flora and fauna, illustrations of interactions and changes within a habitat, or illustrations of food chains. Storyboards, videos, or a series of photographs can be used to illustrate students' understanding of changes or relationships in a natural habitat. Students with strengths in life science may create their own taxonomy keys. They can also share their knowledge by recreating 
an observed or imagined habitat (Maker, 2013). Students can self-select from a teacher-made list of product formats or create their own formats for products.

Learning environment modifications for students with life science abilities must include opportunities for students to observe in natural areas. Videos, pictures, and books about nature and professionals working in life sciences need to be readily available. Natural components such as plants, animals, and artifacts also need to be included in the learning environment.

\section{Developing Physical Science Ability}

Students who possess physical science ability can understand and manage technical mechanisms, create and repair machines or other devices that perform or help perform human tasks, and discern relationships among parts of machines (Maker \& Anuruthwong, 2013). These abilities are used by engineers, inventors, medical technologists, industrial artists, and others who use technical approaches in relating to life, society, and the environment.

Content modifications for students who possess strengths in physical science abilities include demonstrations and teaching basic mechanical concepts. Students learn to apply critical thinking skills by analyzing how machines and technical devices work. Field trips to technology companies or museums and talks by local technology experts, industrial biologists, and medical technologists relate this ability to real-life situations (Tal \& Miedijensky, 2005). Content should include examination of and information about a variety of mechanical or technical solutions to real-life problems (Coxbill, Chamberlin, \& Weatherford, 2013).

Process modifications for students who possess physical science strengths include time to assemble and disassemble real machines. Students can learn computer skills to create real or imagined machines. Participating in whole class discussions about problems related to 
technology and mechanics encourages further investigation of new technology (Okuda \& Shum, 2008).

Product modifications for these students include self-selection of products such as mockups of machines, making models of machines, or developing new technology (Mioduser \& Betzer, 2014). Students with physical science abilities enjoy creating hands-on constructions with moving parts. Illustrations or diagrams of machines and their uses in real-life situations should be choices for these students.

Learning environment modifications for students who possess physical science abilities include machines and illustrations of various technology and mechanical systems in real-life situations as well as videos and books on technology and mechanics. Students need time to explore the machines and mechanical components. Using drafting tools and graphic software allows the students to explore the designs and functions of machines and the use of mechanical methods.

\section{Integrating STEM Areas}

A cross disciplinary approach with math and other content areas was examined by some education practitioners. For example, in engineering education, Model-Eliciting Activities (MEAs) (Chamberlin \& Moon, 2005) were developed, and integration into existing content instruction was recommended as a bridge between math and engineering for students in middle schools. The use of MEAs adds a real-world nature to math problems (Mann, 2006). The Aluminum Bats MEA was given as one example for middle school as an extension of mathematical MEAs (Chamberlin \& Moon, 2005), and is a recognized part of undergraduate education (Moore, 2008). The Aluminum Bats MEA has a materials engineering context in which student teams create a procedure to measure the material qualities of aluminum (Moore, 2008). 
The reason to include engineering in education of the gifted was summarized by (Mann, Mann, Strutz, Duncan, \& Yoon 2011):

The fields of gifted and engineering education share many common interests, and their students share many common attributes. Infusing and making engineering implicit in the K-6 education programs creates opportunities to develop concepts, skills, and habits of the mind that are valuable in all disciplines while providing opportunities to discover and develop talent in the science, technology, engineering, and mathematics (STEM) disciplines. (p.

\section{Profiles of Strengths and Interests}

\section{Profiles from DISCOVER Assessments}

The student profiles of strengths used as examples in this article are summaries of each student's skills and knowledge exhibited during the assessments administered as a part of the CDTIS project. The assessment results included some measures of first-order knowledge developed through experiences and second-order knowledge developed in school (Gardner, 1992). The math assessment required both first-order and second-order knowledge, but was predominantly an assessment of the knowledge gained in school. The spatial analytical performance assessment was a measure of first-order knowledge. Although the life science and physics concept map assessments included some first-order knowledge, they relied on secondorder knowledge, so students' performance was influenced by their schooling. The physical science and life science problem solving assessments relied mainly on first-order knowledge so combining those abilities into the categories of physical science (concept maps and mechanicaltechnical problem solving) and life science (concept maps and life science problem solving) 
provided assessments of both first-order and second-order knowledge in each domain. Spatial analytical abilities were addressed within each area of the profile and more specifically in the analytical discussion along with mathematical abilities. These combinations of assessments help to identify students who have not been exposed to important information in school but have innate abilities in the domains assessed.

When teachers know the strengths of students, they can modify content, processes, and products to engage the students at their levels and encourage them to apply and develop their abilities. In the examples, graphs for each student have a black line across the graph that shows the average scores for the whole group in each area of assessment. Each student's responses were scored as Unknown, Maybe, Probably, Definitely or Wow indicating the level of performance on the assessment on that day. A Definitely rating indicates exceptional talent and a Wow rating denotes exceptionally high ability. An Unknown rating is given when a student's performance does not give enough information to determine whether the student has a particular strength. Maybe is used to indicate that a student might have a certain strength, and Probably indicates that the student is likely to have a strength in a specific ability (Maker, 2019; Wu, et al., 2019). The profiles show each student's pattern of strengths. We have examined three students assessed during the CDTIS project who have very different profiles and have recommended teaching approaches for each student.

\section{Student A Profile}

Life Sciences. Student A (Figure 3) shows understanding of interrelationships, dependencies, and interactions among living and non-living elements of ecosystems. He knows the characteristics of insects, (e.g., types, order, movements, and parts). He demonstrates the ability to group and categorize living things according to noticeable characteristics. He 
understands environments in which certain living things are found. He is a keen observer of elements of his environment and demonstrates a high level of understanding of the natural world. Student A has the ability to understand a current problem in life science and show graphically the factors that may contribute to the development and resolution of the problem. He understands the impact of temperature change on the earth's environments. Student A makes appropriate connections among important ideas, and the connections he makes are valid and show deep understanding of relationships between core ideas.

Physical Science. Student A understands ways to make mechanical constructions stable and strong. He understands the relationship between the design of a device or other construction and its movement. He knows how motors, gears, and remote-control devices operate, and can design machines or other devices that function well. He demonstrates more advanced mechanical and technical skills than other students his age. Student A can describe graphically the laws of motion and the effects of forces on the motion of objects. His connections among ideas in physics are valid and show deep understanding of relationships between core ideas, (i.e. laws of physics).

Math. Student A has a strong number sense; He understands and applies fractions, algebraic concepts, and exponents in complex mathematical problems. He uses a variety of representations to explain math concepts such as graphs, models, and diagrams. Student A uses a variety of strategies when solving complex math problems. He clearly understands patterns in geometric figures and can construct figures in a logical sequence. Student A produces graphic likenesses of spatial information.

Analytical. Student A uses logical strategies for analyzing relationships among shapes and patterns. He recognizes different examples of the same attribute. Student A's strengths in 
analyzing hierarchical relationships among ideas are consistent across math, physical sciences, and life sciences. He applies critical thinking skills to evaluate potential solutions and select the most promising one.

Creative problem solving. Student A generates many detailed and effective solutions. In both life sciences and physical sciences, he makes many appropriate connections between ideas that may seem unrelated to others. Student A creates many geometric representations of complex patterns in nature. He demonstrates the ability to analyze mathematical structures and patterns of a problem. He shows a variety of creative ways of solving mathematical problems. He identifies and creates a variety of mathematical problems and develops original solutions to them. Across content areas, Student A applies critical thinking skills to evaluate potential solutions and select the most promising ones. He generates unique hierarchical relationships among ideas and concepts.

Motivation. Student A shows involvement and continuously works on tasks presented. He persists on difficult tasks even when setbacks occur. He follows through to completion. Student A shows enjoyment of complex problem solving and has little need for external motivation to follow through on difficult tasks.

Programming for Student A. Student A has many strengths in different areas and has high levels of both first- and second-order knowledge. His performance on the DISCOVER assessments in STEM administered during the CDTIS project placed his abilities at the Definitely level in math, spatial analytical, life science, physics concept mapping, and mechanical-technical problem solving, and at the Wow level in the life science concept mapping. Student A needs challenging content and a teacher who allows him to choose what he studies. He may need guidance, but can develop his own processes for creating a product to share his 
learning with an audience. He may be a mentor to other students, but also needs time to pursue his own interests. Student A would benefit greatly from working on a real-world problem and meeting professionals who work in one of his fields of interest.

\section{Student E Profile}

Life Science. Student E (Figure 4) shows understanding of interrelationships, dependencies, and interactions among living and non-living elements of ecosystems. She knows the characteristics of insects (e.g., types, order, movements, and parts). She demonstrates the ability to group and categorize living things according to noticeable characteristics. She understands environments in which certain living things are found. She is a keen observer of elements of her environment and demonstrates a high level of understanding of the natural world. Student E has the ability to understand a current problem in life science and show graphically the factors that may contribute to the development and resolution of the problem. She understands the impact of temperature change on the earth's environments. Student E makes appropriate connections among important ideas, and the connections she makes are valid. They show deep understanding of relationships among core ideas. She analyzes hierarchical relationships among ideas.

Physical Science. Student E demonstrates a wide range of mechanical and technical skills. She shows ability to incorporate mechanical and technical skills in the development and elaboration of new products.

Math. Student E understands fractions, simple algebraic concepts, and exponents. She has an awareness of numbers.

Spatial Analytical. Student E identifies a variety of ways that shapes can be combined. She solves complex problems quickly. Student E discovers promising ideas and problems that 
need to be solved. She generates many solutions to problems. Student E can recognize different examples of the same attribute. She applies reasoning skills with patterns, shapes, figures, and ideas.

Creative Problem Solving. Student E creates original ideas that have interesting details and she notices characteristics of living things. She shows understanding of the relationships between patterns in nature. Student E identifies a variety of ways that shapes can be combined. She solves complex problems quickly. Student E can transform a visual image into two and three-dimensional forms. Student E creates many geometric representations of complex patterns in nature. She applies critical thinking skills to evaluate potential solutions and select the most promising one.

Motivation. Student E continuously works and is involved in tasks. She shows enjoyment of complex problem solving. Student E generates many solutions to problems.

Programming for Student E. Student E's assessment shows her Wow level abilities in spatial analytical problem solving and life science concept mapping and Definitely level in life science problem solving. Her abilities in math are rated at a Maybe level, which is slightly below average, while her abilities measured by the physics concept mapping assessment are rated at the Unknown level. Because both math and physics concept map assessments require second-order knowledge, she may need additional teaching in those areas. Using her innate strengths in spatial analytical problem solving, life science concept maps, and life science problem solving abilities will assist her in developing second order knowledge in physics and math. When she is asked to solve real-world problems in her areas of strength, she will be more engaged in learning skills necessary to solve problems in her weaker areas.

\section{Student P Profile}


Life Science. Student P (Figure 5) understands current problems and hierarchical relationships among ideas in life science. She makes valid connections between life science concepts that show understanding of core ideas. She also understands elements of habitats for specific plants and animals.

Physical Science: Student P demonstrates a wide range of mechanical and technical skills. She shows ability to incorporate mechanical and technical principles in the development and elaboration of new products. She knows how motors, gears, and remote-control devices operate, and can design machines with gears powered by motors. Student $\mathrm{P}$ also incorporates mechanical and technical skills when creating and elaborating on new products.

Math. Student P understands fractions and algebraic concepts. She uses a variety of representations to explain math concepts such as graphs, models, and diagrams. She also sees patterns in geometric figures and can construct figures in a logical sequence.

Spatial Analytical. Student P uses logical strategies for analyzing relationships among shapes and patterns. She identifies ways that shapes can be combined.

Creative Problem Solving. Student P makes products or solutions that are new or different. She transforms a visual image into two and/or three-dimensional forms. Student P makes unique products. She can create geometric representations of complex problems in nature. She develops effective solutions. Student P makes appropriate connections between ideas that may seem unrelated. She creates complex designs.

Motivation. Student P shows involvement in tasks and continuously works. She persists on difficult tasks even when she encounters setbacks. She follows through to completion and enjoys complex problem solving. She has little need for external motivation to follow through on difficult tasks. 
Programming for Student P. Student P demonstrates first- and second-order knowledge in math and first-order knowledge in spatial analytical and mechanical-technical problem solving, scoring Definitely in all three areas. For the life science and physics abilities assessed through concept maps, Student P scored at the Maybe level in both areas. Her performance may indicate that she did not understand the task of creating concept maps or it could indicate that Student P lacks second-order knowledge in these areas. This low level of knowledge may also influence her Maybe score in life science problem solving. Because Student P has a Definitely level rating in creative problem solving (using first-order knowledge) in three areas, capitalizing on those strengths is important when teaching new knowledge or skills related to life science concept maps, physics concept maps, or life science problem solving.

Teaching strategies and curriculum modifications for exceptionally talented students in STEM are all included when teachers use the Real Engagement in Active Problem Solving (REAPS) model, which includes the DISCOVER curriculum model. The REAPS model was used by the teachers in the CDTIS project during school year programs after students were assessed and after some of them participated in the KEYS internship program on the campus of the R1 university (Maker, 2016). In the REAPS model, real-life experiences and problem solving engage all students and extend their learning in meaningful and challenging ways. The REAPS model is described in the following section.

\section{The REAPS Model}

Real Engagement in Active Problem Solving (REAPS) is an educational model designed to develop students' ability to solve real-world, complex problems and create solutions that are effective, efficient, original, ethical, elegant, or economical (Maker, 1993; Maker, et al., 2015a; Maker, 2019). The REAPS model was developed by Maker and her colleagues in 2004 (Maker 
\& Zimmerman, 2008; Maker, et al., 2015b; Zimmerman, Maker, Gomez-Arizaga, \& Pease, 2011) because the DISCOVER approach alone did not provide enough guidance for teachers in developing real-world problem solving. The REAPS model is comprised of three teaching models and based on the general education curriculum: (a) DISCOVER, (b) Thinking Actively in a Social Context (TASC), and (c) Problem-Based Learning (PBL). The three teaching models have different ways to achieve the shared and ultimate goal of developing problem-solving skills. REAPS has been implemented at several grade levels, from elementary through high school; and in countries around the world, including the United States.

The research team of Maker, Zimmerman, and colleagues conducted research to determine whether a teacher's use of the REAPS model improved their students' integration of state mandated science standards and concepts. In the first study, the researchers used concept mapping as both pretests and posttests to measure students' understanding of science that deals with the earth's physical structure and substance, its history, and the processes that act on it. Two classroom teachers and their classes were involved with two renowned experts, one in the field of education of gifted students and one scientist, who supervised, mentored and collaborated with the teachers in all aspects of implementation of the REAPS model. Concept maps were scored separately using two methods. Researchers found significant increases between pretest and posttest scores in both classes as well as a high correlation between the two scoring methods (Zimmerman, et al., 2011). In both methods, students' concept map scores were based on (a) the number of connections they made between concepts, (b) the hierarchies of concepts they identified, (c) the number of examples of concepts they identified, and (d) the connections they made from one major hierarchy to another (cross links). Significant differences were found in the number of connections and the number of examples, but not in the hierarchies or connections 
from one hierarchy to another. Researchers concluded the students needed more time to demonstrate changes in the hierarchy and cross links, but also noted that students' maps were more closely related to the criterion maps developed by teachers and the scientist at the end of the unit than at the beginning, demonstrating their increases in expertise (Sternberg, 1999; Zimmerman, et al.).

In a second study, the same group of researchers worked closely with teachers in grades K through 6 to implement REAPS in an elementary school in Australia. Students in 10 classrooms participated in REAPS experiences for either two terms (2.5 weeks) or four terms (10 weeks). Alhusaini (2017) found that all students showed progress in creative problem solving in science, and that those who had participated in REAPS for a longer duration demonstrated significantly more growth in creative problem solving in science $(p=0.001)$, showing that their growth could be attributed to the use of the model, not just to maturation and the usual methods of teaching. In both of these studies, the use of open-ended problem-solving assisted students in developing their knowledge successfully (Alhusaini \& Maker, 2011; Sierra-Fernandez, \& Perales-Palacios, 2003; Zimmerman, et al.).

REAPS was implemented in two high schools in New Zealand in a rural area with high percentages of Maori students. The Ruamano Project was funded by the New Zealand Ministry of Education through its Teacher-Led Innovation Fund. Teachers who were interested in creative and new practices for cultivating learner outcomes could receive funding to develop their ideas (Berryman, SooHoo, \& Nevin, 2013). Before and during the project, community representatives were actively engaged in planning and implementation. Meetings were set up at the school and in local meeting halls to discuss the coming project, and the whole school, including teachers, administrators, students, and parents participated in the process. One 
important component was that the community leaders contributed to the choice of a problem to solve. Much community assistance with the local organization of science testing sites and field work was continuously evident during the project. The Māori scientific perspective was maintained by the Northland Regional Council (NRC) and they were present with students. A team of researchers, administrators, science teachers, and teachers of gifted students implemented REAPS with 90 Year 9 students: 39\% Maori and 12\% Māori boys. Data were collected to assess the effectiveness of the use of the REAPS model in improving the engagement and achievement of potentially gifted Māori boys. The Year 9 National Standards achievement objectives in science showed that students involved in the REAPS program demonstrated important increases in scores. For instance, prior to implementing REAPS, $40 \%$ of Māori were achieving below the standard, 53\% at the standard, and 7\% above the standard. After implementing REAPS, 75\% of Māori boys were performing at the standard and 25\% were performing above the standard (Riley, Webber, \& Sylva, 2018). After the project was implemented, one Māori boy was eligible for the top mathematics group, and two Māori boys were identified for the top English class.

Researchers also interviewed teachers, students, parents, and community members during the project; they were asked for their perspectives about the planning and implementation of REAPS. One of the key questions for teachers was how the model was adapted for their cultural context. They identified the following key themes: alignment with the curriculum, modification of the process based on student ability, and community and iwi (i.e., social unit in Maori culture) involvement. In focus group interviews, several teachers talked about how REAPS supported the achievement of Māori boys through collaborative problem-solving; this method engaged capable students while involving everyone in solving real problems that impacted their lives. One teacher 
said "Our boys tend to enjoy learning through doing, working with others to solve problems." (Riley, et al., 2018, p. 81) Teachers recognized the importance of being learners beside their students and with each other. Their statements demonstrated an ethic of caring for students and showed that they practiced nurturing relationships focused on caring and connectedness. Teachers agreed that understanding and honoring a multitude of ways of knowing and imparting knowledge was important. Furthermore, they agreed about the value of fully interacting with, developing strategies, and empowering students to work actively to solve problems that have a direct impact on their community, their family, and their lives (Webber, et al., 2018). All three science teachers identified engagement in learning as the greatest change in their students, especially the Maori boys (Riley, et al.)

Students who were interviewed expressed similar beliefs about their engagement, saying that the hands-on experimentation and investigation of problems that impacted their lives were important aspects of their involvement. For instance, one student said "We went out and actually investigated what the problem was instead of, you know searching it up on the internet and just viewing it from the computer." (Riley, et al., p. 83) Another area identified by both students and teachers was working in groups to solve the problem and create presentations about their solutions. Students said that working in groups was both meaningful and supportive. Many students articulated that they felt a profound sense of community and a sense of belonging to the whakapapa (genealogy) of their environment, and that they had gained a new scientific understanding of the changes within their ecosystem. Some of the students communicated their belief in the importance of field work and their desire to further the research about water quality in their local environment (Webber, et al., 2018). 
Surveys of community members showed they agreed on the value of engaging students in solving real community problems. Many community members said student involvement in conservation was the greatest benefit of the project, for both the students and the community, because it would not only benefit them but would benefit future generations.

Another aspect of REAPS viewed as valuable was involvement in stakeholder groups, which was described by teachers, community members, parents, and students as an important way to enable students to see issues and problems from several perspectives. After students developed their solutions to the problem from their stakeholders' perspectives, they presented to the community, and community members evaluated their presentations. Community members noted that because they investigated different points of view, students could challenge existing theories and policies. They also could contribute to more effective resource management in the community (Riley, et al, 2018).

The TASC model was used as a process component and interactive guide embedded in REAPS. Wallace (2008) developed the TASC model to help students improve their thinking skills while engaging actively in solving problems within a social environment. In this model, students used eight different steps to guide their learning processes: gather and organize, identify, generate, decide, implement, evaluate, communicate, and learn from experience. The TASC steps have been designed for use in a circular way to allow students to monitor their progress in problem solving and return to particular steps at a higher level of understanding (Wallace, Maker, Cave, \& Chandler, 2004; Maker, et al., 2015b). The main reason for using this model was to help students develop thinking, problem finding, and problem-solving skills. The TASC wheel (Figure 6) was designed to help students stay organized, active, and focused as they worked on their projects. Students need to progress around the circle as a general strategy; 
however, they can return to earlier steps when needed because the process of problem solving is recursive (Maker, et al., 2015c; Wallace, et al., 2004).

The DISCOVER model has two major components: a problem continuum (Maker, 2005; Maker, et al., 2015b), and a theoretical grounding in the Prism of Learning (Prism) (Maker, et al., 2015a). When using the DISCOVER model, teachers emphasize the use of multiple abilities to solve a variety of types of problems within the context of solving the local problem(s) identified. Use of the DISCOVER problem continuum helps teachers and students progress gradually from solving closed problems with right answers (common in schools) toward the solving of open-ended problems that are like the problems encountered in daily life. When using the DISCOVER model, teachers also (a) use active hands-on learning with 'tools' or symbol systems of each of the domains of ability, (b) integrate the culture of the students and the local community into the curriculum, and (c) plan curricula around state standards and abstract themes (Maker, et al., 2008; Maker, et al., 2006).

The PBL approach was included in this model because it provided a setting in which knowledge and skills were applied to solve a real-world problem. This model is similar to both the TASC and DISCOVER frameworks in that it includes these elements: an ill structured problem, real life-based content, students' culture and background, and self-directed learning. Using this model, educators addressed content, concepts, and standards. They also focused on developing students' thinking skills and problem-solving abilities (Maker, et.al., 2015c). Problem-solving skills include defining ill-structured problems, referred to as "problem finding", an element considered important for exceptionally talented students (Gallagher, Stepien, \& Rosenthal, 1992). 
Several researchers have found positive results when PBL was used in high schools, universities, and across different academic areas: (a) students increased their ability to deal with uncertainty, and acquired skills in self-directed learning (Hung, 2011); (b) students could apply their learning beyond their unit of study and stay within the context of the problem (Trinter, Moon, \& Brighton, 2015);(c) students in PBL programs could construct knowledge and produce more sophisticated explanations when they were assessed in problem-solving contexts, but not in the context of multiple-choice examinations (Hmelo-Silver, 2004; Schmidt, DeVolder, De Grave, Moust, \& Patel, 1989; Schmidt, Machiels-Bongaerts, Hermans, ten Cate, Venekampe, \& Boshuizen, 1996); and exceptionally talented high school students retained information better when in PBL classrooms than when taught with conventional methods (Dods,1997). For instance, during a PBL mathematics unit study, researchers found that students could connect patterns outside of the mathematics classroom in other academic settings, as well as in the real world. The construction of ill-structured problems allowed for multiple and accurate mathematical interpretations and responses. More information about PBL can be found in other publications (Gallagher, et al., 1992; Gallagher, 1997; Gallagher, \& Horak, 2011).

More information about the REAPS model, with examples of its implementation and research on its use, can be found in several publications (Alhusaini, 2016; Gomez-Arizaga, Bahar, Maker, Zimmerman, \& Pease, 2015; Jo \& Ku, 2011; Maker, et al., 2015a; Maker \& Wearne, in press; Maker \& Zimmerman, 2008; Maker, Zimmerman, Gomez-Arizaga, Pease \& Burke, 2015c; Reinoso, 2011; Zimmerman, et al.; Wu, et al., 2015; Wu, et al., 2019).

\section{Developing a REAPS Teaching Unit}

High school teachers who participated in the Cultivating Diverse Talent in STEM (CDTIS) project echoed the question asked by most teachers: Can the REAPS model be used in a 
classroom in which I am required to teach certain standards? The short answer is yes and goes far beyond addressing state and local requirements. The REAPS model is structured in a way that allows students to collaborate, research, systematically build criteria, and individually dive more deeply into curriculum content.

Teachers in the CDTIS Project partner schools planned comprehensive REAPS Case Studies based on required curriculum content, state standards, and performance objectives. Teachers developed a case study that helped them understand their chosen problem at a deeper level and how it was connected to curriculum standards, performance objectives, and outcomes (NAGC 2010; Maker, 2016; Maker, et al., 2015c).

Case studies were used as a fictionalized description of a real-life problem or conflict; however, not all case studies need to be fictionalized. Case studies include noticeable problems or failures, and unknowns that force participants to make decisions, as people do in real life, based on imperfect knowledge of the situation, personal beliefs, and cultural values (NAGC, 2010). They are realistic and challenging, and promote insightful thinking. As the education research team developed case studies with the teachers, we asked them to pose a problem that their students could possibly solve or a conflict they must undertake and resolve. No "right answer" was available for the problem posed (Maker, 2016; Maker and Zimmerman, 2008; Maker, et al., 2015b; Maker, et al., 2015c; Reinoso, 2011; Zimmerman, et al., 2011; Alhusaini, 2016) Just as in real-life, alternative solutions or resolutions can be created. Most real-life problems or conflicts have more than one possible resolution; they are not simple (Van TasselBaska, 2002). If a case study is too simple, many solutions are not needed and will not enable the teacher to meet curriculum requirements within a unit of study. The scenarios within the case study are realistic and in general set the stage for real decisions and actions taken. Case studies 
are used as a narrative and include a series of events surrounding a specific problem or conflict. The case study includes details and forms a rational story, and are designed to encourage active participation on the part of the teacher and learner; the teacher leads students to find a resolution to the problem presented. We found they were helpful in building the confidence of both teachers and participants in their ability to deal with similar problems in real-life. Case studies stimulated interaction and helped set a good environment for focused dialogue (Herreid, Schiller, \& Herreid, 2012). For the REAPS teaching units, the text was short, two or three pages, and had a beginning, middle and end (Maker, et.al., 2015c). For a detailed list of the questions for developing a case study, see Table 1 .

After 'the problem' within the case study has been developed, five to seven stakeholder groups are identified. In REAPS students work together with a common focus and are divided into stakeholder groups. A stakeholder is defined as a group of individuals or organizations who are impacted by the outcome of a decision. They have an interest in the success of the problem solution and can be within or outside the organization that is sponsoring the problem-solving project. Stakeholders can have a positive or negative influence on the project; either way, they are very interested in the project and its proceedings (Freeman, 1994). For example, in a unit about plastics, stakeholder groups were the Environmental Protection Foundation, Concerned Residents' Association, Department of Resource Conservation and Environmental Protection, Municipal Commission of Tourism Development, Petroleum and Chemical Industry Federation, and Plastic Processing Industry Association.

At the end of the unit of study the students present their solutions to a panel of experts, a commission, orchestrated by the teacher. The commission members listen, and they have an opportunity to ask the stakeholders questions, generate discussions about their presentations, and 
focus attention on a particular position or belief. At the end, the experts vote to decide which solutions to recommend, and explain why. Another discussion among all stakeholder groups ensues, in which the students formulate new questions and come to a final decision or solution as a whole class based on all presentations and the comments of the panel of experts. By using stakeholder groups, teachers require students to take perspectives including ethics, morals, and values other than their own. Students see how these differences in perspectives influence decisions and begin to learn how they can be resolved.

\section{Sample Case Study}

Following is the overview, problem statement, stakeholders, focus questions, and resources that were given to a high school class of students in $11_{\text {th }}$ grade. They kept the document and referred to it throughout their problem-solving process.

Overview. The goal of this activity is to experience the REAPS model by solving an ecological and chemical problem related to an environmental issue that is important to local and state interest groups or stakeholders. You will be asked to join a stakeholder group to learn and develop a solution to the ecological and waste management problems associated with high concentrations of copper (II) chloride in an old tailings pond owned by the Santa Cruz River Mine. You will be randomly assigned to a group of 4-5 students. You and your team will gather and organize information, identify and define the problem, generate solutions, decide on the best solution, develop a presentation about your proposed solution, evaluate your presentation, and reflect on your learning.

The problem. Several stakeholder groups are interested in purchasing the Santa Cruz River Mine. The City Council will award the rights to purchase the mine to the stakeholder group that develops a method to clean up the 50 million-liter tailings pond that has a copper (II) 
chloride concentration of 50,000 ppm. The method must be as cost effective and environmentally friendly as possible. The tailings pond is lined with a chemical resistant/leak proof lining. One thing to consider is the long-term effect of acid rain on the products of the copper (II) chloride cleanup efforts.

Stakeholder groups. Some stakeholder groups in REAPS units had both fictional and real qualities so students could easily research points of view, interests in the problem, and influential means. Descriptions of the stakeholder groups included a short paragraph or two describing the organization and included key questions that helped guide students in their research about the problem within the context of the stakeholder.

Freshwater Farms. Freshwater Farms is a multistate aquaculture fish farming group based in Ohio. Freshwater Farms is a vertically integrated hatchery, grow-out, processing, marketing, and retail operation. They are the only producers of trout products in Ohio. The fiveacre farm is the state's largest indoor fish hatchery, where they raise up to 100,000 pounds of fish yearly. The fish are raised both indoors and outdoors year-round. The production in Arizona will be exclusively outdoors, in the cleaned up mine tailings pond. Questions to consider: How would left-over copper contaminants in the tailings pond affect trout production for human consumption? What other factors affect aquaculture water quality?

Robson Resort Communities/ Quail Creek. Amid the natural beauty of the rugged Santa Rita Mountains, you can step outside and right into the scenic vistas of Madera Canyon, a wonderland for bird watchers, outdoor lovers, and nature enthusiasts. Located only 25 miles south of a large city, Quail Creek is a world of its own within the friendly town of Sahuarita, in the Green Valley area. Quail Creek plans to turn the tailings pond into a miniature Great Salt Lake for members to experience floatation therapy. Questions to Consider: Is reclaimed mining 
land safe for developing a retirement community? How would remnant copper (II) chloride interact with the Epsom salt that will be used in the proposed floatation therapy pond?

Parks and Recreation Department. The Parks and Recreation Department of the large city plans to develop a large naturalistic area that includes an urban catch-and-release fishing lake and bike path. The City Parks and Recreation Department provides a variety of parks, recreation facilities, and experiences equitably throughout the community. Programs are developed and maintained to the highest quality, ensuring a safe environment with exceptional service resulting in the development of lifetime customers. Services demonstrate a positive economic investment through partnerships with other service providers, both public and private, ensuring a high quality of life for residents of all ages and abilities. Questions to Consider: How will the native flora and fauna fare in copper-rich soil and water? Is reclaimed mining land safe to turn into a natural area?

Save the Scenic Santa Ritas. Save the Scenic Santa Ritas (SSSR) is a volunteer-based, non-profit organization, based in a large city in Arizona. Its mission is to protect the scenic, aesthetic, recreational, environmental, and wildlife values of the Santa Rita Mountains, Patagonia Mountains, Canelo Hills, and San Rafael Valley through education and outreach, including protection of these areas from degradation due to mining activities. SSSR has expanded its area of protection to the Santa Cruz River Mine and wants the EPA to condemn the entire mine and surrounding area, because they claim that no solution exists to properly clean up the tailings pond in an economical, ethical, and environmentally friendly way. SSSR wants the copper ions to be chelated and then left alone. Questions to Consider: What happens to abandoned mines? Who would be responsible for future cleanup/damages, if the mine were left abandoned and something happened? 
Freeport-McMoRan Inc./Waste Management. Freeport-McMoRan Inc. (FCX) is a premier US-based natural resources company with headquarters in Arizona. FCX operates large, long-lived, geographically diverse assets with significant proven and probable reserves of copper, gold, molybdenum, cobalt, oil, and natural gas. FCX has a dynamic portfolio of operating, expansion, and growth projects in the copper industry. FCX is the world's largest publicly traded copper producer. FCX wants to extract the remaining copper ions from the lake using new, solar-powered technologies. Once the copper has been removed, FCX will sell the mine to Waste Management to turn into a green landfill. Questions to Consider: What considerations must be made to turn a mine into a landfill?

\section{REAPS Teaching Unit}

A REAPS unit description includes (a) macro concepts; (b) framework benchmarks, (c) overall goal; (d) discipline-based concepts (PBL); (e) process concepts (TASC); (f) product concepts (DISCOVER model, including the Prism abilities); (g) materials; (h) case study; (i) activities and lessons, designed to include components of TASC, PBL and DISCOVER. Macro concepts have been developed to identify abstract ideas that cut across or unify different strands of the curriculum, such as systems, interdependence, and change. Benchmarks are based on the curriculum standards and other required experiences or conditions and are smaller units of measurement. After the teachers designed their units using the required components, they were actively engaged in the process of implementing REAPS in the classroom. When teachers help students learn a structured problem-solving process they can use on their own and in groups, all the processes recommended for gifted students are included and teachers do not need to monitor the students at all times. We have found that the TASC model (Alhusaini, Maker, \& Alamiri, in review; Maker \& Pease, 2008; Maker \& Zimmerman, 2008; Wallace \& Maker, 2007; 
Zimmerman, et al., 2011) is a practical and effective model to be used with learners at all levels of education, especially when combined with Problem Based Learning (PBL) and the DISCOVER model. PBL provides substantive content and connections to real-world problems, DISCOVER provides guidance for teachers in designing problems for students to solve, and TASC provides a process for solving them.

Teachers designed their units of study to incorporate Thinking Actively in a Social Context (TASC) and were encouraged to outline their course of action. TASC was a flexible circular model with steps to guide students throughout the course of the REAPS unit. The eight steps were interactive and nonlinear: (a) Gather and Organize: What do I (we) know about this? (b) Identify: What is the task? (c) Generate: How many ideas can I (we) think of? (d) Decide: Which is the best idea? (e) Implement: Let's do it! (f) Evaluate: How well did I (we) do? (g) Communicate: Let's tell someone; (h) Learn from Experiences: What have I (we) learned?

During the Gather and Organize step, the teacher presented the problem to the whole class, and the students generated information about what they knew, what they needed to know, and possible sources for the information they needed to know. Data were collected from various sources such as the Internet, books, newspapers, interviews with experts, questionnaires, observations, experiments, and field work. This step was revisited throughout the unit. Students gathered real data. Participants were placed in Stakeholder groups after much of the general research in Gather and Organize was completed. After the students were placed in the stakeholder groups, research and data collecting continued, emphasizing the general vision of that particular stakeholder group. For example, if a stakeholder group happened to be a lobbyist for the Plastics Chemical Commission, the focus of that group was different from the Living Green Advocacy stakeholder group. Students who were in the stakeholder group Freshwater 
Farm investigated water for quantities of copper contaminants, assessed the quality of certain aspects of their immediate environment, observed people, listened to guest scientists, and interviewed community members.

After the students were placed in stakeholder groups and generated more data, they continued to the Identify step. Students were instructed to write a statement of the problem based on the stakeholder's point of view, created five questions based on the statement of the problem, selected one question to answer, and returned to the Gather and Organize step to collect more data based on the question they selected. The Save the Scenic Santa Ritas stakeholder group chose this question to investigate and solve: How can we convince the EPA to close the mine and surrounding areas? On the other hand, the Freeport-McMoRan Inc./Waste Management group chose to consider a different question: What considerations must be made to turn a mine into a landfill?

The young scholars continued to the Generate step. They brainstormed and generated a long list of ideas and contributed to the agreed upon focus question. The students decided to assign roles to their members. For example, a scribe was needed to serve as secretary, and an enforcer made sure everyone was contributing to the group and collected pieces of data from each member. In one classroom, stakeholder groups included a cheerleader and encouraged their members to remember 'that all ideas were acceptable'. In the REAPS model, rules for generating ideas were shared with the students: (a) no evaluating; (b) no elaborating; (c) accept wild and crazy ideas; (d) go for quantity, not quality; (e) hitchhiking is acceptable. Students were encouraged to brainstorm a few different times during this step.

The Decide step of TASC was a challenge for students because collaboration and decision making played a significant role when deciding on the best idea. Students created, with 
their teacher's help, a list of criteria that assisted them in selecting the best idea. The criteria were developed by the teacher and students with each stakeholder group so that all ideas were considered; and insured that curriculum, research focus, and various perspectives were integrated. Some possible criteria included the following: (a) Is the solution practical? Is it doable? Is it realistic? Is it possible? (b) Does it have a long-term effect? (c) Does it protect life in the future? Does it harm any living beings now? (d) Does it preserve the environment for our children and grandchildren? (e) Is the solution one that would bring people together? (f) Is the solution fair to all stakeholders? (g) Is the solution cost-effective? After the members of the group agreed upon the criteria, each student scored every idea and used the following scale: $0=$ below average/poor, $1=$ average/possibly, and $2=$ above average/excellent. Next they collaborated, totaled their scores for each idea, and decided which of the excellent solutions could be combined into one solution, if necessary, and then decided on their final solution. As a stakeholder group, they decided on a clear and concise solution statement. The teacher reviewed each stakeholders' solution statement and criteria; then discussed any changes, deletions, or improvements to the statement. Solution statements were presented and agreed upon before the students continued to the next step. Sometimes stakeholder groups decided they were not ready to make a decision, so they returned to the Gather and Organize step to collect more information.

Generally, this is the step in which field work begins to play a larger role, although it certainly can be a part of Gather and Organize or any of the steps. Field work is an important aspect of the REAPS model. Although whole class field trips can be useful, the field work component is what allows students to take advantage of direct investigation, research, observations, and data collection. To prepare for field excursions during class time, students are encouraged to bring their focus questions on clipboards, and to have cameras, recording devices, 
field notebooks, pencils, and any instruments that are needed for their investigations. Some field work is a part of the school day, while in other cases groups may decide to continue after school or on weekends. Field work also includes interviews with local groups and individuals, surveys that are distributed, and lectures attended by the students. For example, Save the Scenic Santa Ritas and Robson Resort Communities/Quail Creek decided to explore the Santa Ritas: they took both soil and water samples, took pictures of surrounding areas, sketched landscapes, and took measurements surrounding the water source. All stakeholder groups toured the historical sites, listened to park rangers, and heard a presentation by a scientist who was conducting research through a state grant.

After adequate data were collected and research completed, the students were excited to move to the Implement step. At this step, diagrams, plans, flowcharts, and models were developed. The implement step was an opportunity for students to show their many abilities in STEM and other academic areas such as linguistic, spatial, social studies, architecture, and music. Students in each stakeholder group looked at their statements of purpose and decided whether to construct a diagram, flow chart, three-dimensional model, or a different way to present their solutions. These tools were used to communicate the solutions to problems visually. Again, all groups can revisit the Gather and Organize step to gather more insights into their solutions as they devise their models. The students generally take a lot of time building their models and constructing flowcharts. They often make more than one product.

The teacher held a large group discussion about the importance of each group's selfevaluation of its products, problem-solving processes, and implementation at the end of the Implement step. In this discussion, the students and teacher generated a list of criteria everyone thought would be appropriate for evaluating the products at the next step, Evaluate. When 
developing their criteria, teachers asked their students to include criteria such as these (Table 2):

Is it original or creative? Did you use teamwork? Is there evidence of details in your thinking? Is your solution feasible or possible? Is there a negative impact? The teacher and students collaborated and generated a list of criteria that could be used to evaluate the group's problemsolving process: cooperation, patience, use of trial and error, persistence, concentration, willingness to listen to opposite opinions, attitude toward others' opinions, acceptance of others, resolution of disputes, and motivation. Each group chose at least three of the criteria, criteria they believed were the most important in deciding on the overall quality of their product(s) and process. Finally, the students analyzed their implementation and made decisions for improvement. They discussed criteria such as feasibility and impact of the solution. If a group scored low in feasibility, the group members could see a possible impact on their success during the communicate stage when they discussed their results and solutions with the panel of experts. This realization often resulted in questions such as "What could we change to improve the feasibility of this solution?" Some groups may even go back to the Gather and Organize step to readdress a few concerns they missed in their original research.

During the Communicate step of TASC, students were given time to practice or rehearse their presentations. This is the time to make changes and students were encouraged to include at least two or more of the following products in their presentations to show their abilities: diagrams, plans, flowcharts, PowerPoint presentations, experiment demonstrations, posters, oneact plays, music, artwork, and three-dimensional models. After adequate time was given to rehearse their presentations, each stakeholder group presented its research, evidence, data, products, and processes to advocate for its solution to the panel of experts. Students also shared their criteria and results. The panel of experts gave each stakeholder group feedback, asked 
questions, and held a general discussion, allowing ample time for each group to provide support for its solution.

Some general feedback from the teacher on the presentations was based on curriculum standards and discussed with the whole class. Each individual stakeholder group was given individualized feedback as well. Here is one teacher's list of strengths and improvements:

Strengths

- Creative Solutions

- Detailed models that communicated the important ideas

- Logical flow charts

- Solutions are implementable

- Solutions were appropriate for their stakeholder groups

- Good use of internet video clips with real time voiceovers

- Good introductions of stakeholder groups

- Slogans or Logos were used in most stakeholder group presentations

- $\quad$ Speaking voices were clear and well-rehearsed

- Images are memorable and can make a strong point.

Improvements

- Some slides had way too much text with no visuals

- Some slides needed more contrast so that text would stand out

- Make sure you present to the audience and not at the slides on the screen

- Pay attention to pacing of your speech

- Make sure your slides are ordered and ready; show one slide at a time

- Do not have presentation notes visible on slides 
Members of the panel of experts were encouraged to create criteria for stakeholder feedback that could be given to each group at the end of its presentation. Table 3 is an actual document written by one panel of experts.

At the final step, Learn from Experience, all participants reflected on the whole process and talked about their learning. Each group reviewed the TASC Wheel and reflected on each step of the process, sharing ideas about what they learned. Group members discussed how they worked together more effectively, for example, how they learned more about the role of environmental issues in land management, development, and tourism. Individuals and groups reflected on the ways this process could be used in other content or subjects. Stakeholder members discussed how their ideas and activities improved. Each student was asked to reflect by writing a response to this question: What was the most important thing you learned about yourself during this REAPS unit? Finally, technology played a role as students formed online chatrooms so they could keep informed about their solutions and communicate their experiences as they applied in other social and educational situations.

\section{Conclusion}

In this article, we have provided recommendations for teachers in two sections. In the first section, the emphasis was on ways to develop abilities of students and groups of students who have similar strengths, using the DISCOVER teaching model. We also provided ways to build on strengths while at the same time bringing up the weaker areas. Reports such as the ones included in the article are provided to regular classroom teachers, parents, and the students themselves. They also are provided to teachers of advanced classes and in special programs for exceptionally talented students to enable them to use the results of the assessments. In the second section, the emphasis was on the teaching model, Real Engagement in Active Problem Solving 
(REAPS), which integrates DISCOVER into a four-component model because it is a method for accommodating the needs of exceptionally talented students in the context of either general or special classrooms, and can also be a way to integrate the recommendations for developing the strengths of individuals and groups as they participate in real-world problem solving. The REAPS model also has been successful as a way to identify exceptionally talented students who are not identified by other methods. Interest and involvement in solving a real-life problem that students are passionate about solving can help hidden talents to emerge (Gallagher \& Gallagher, 2013; Riley, et al., 2017; Webber, et al., 2018). Support for this perspective can be found in several studies in which curricula and teaching strategies recommended for exceptionally talented students were effective in increasing the achievement of all students (Fraleigh-Lohrfink, Schneider, Whittington, \& Feinberg, 2013; Hallett \& Venegas, 2011; Lee, Olszewski-Kubilius, \& Peternel, 2009; VanTassel-Baska, Bracken, Feng, \& Brown, 2009).

\section{References}

Alfaiz, F. S., Pease, R., \& Maker, C. J. (2019). Culturally responsive assessments of physical science abilities: Development, field testing, and implementation. Manuscript submitted for publication.

Alhusaini, A. A. (2016). The Effects of Duration of Exposure to the REAPS Model in Developing Students’ General Creativity and Creative Problem Solving in Science. Unpublished Doctoral Dissertation, University of Arizona, Tucson, USA.

Alhusaini, A. A. \& Maker, C. J. (2011). The uses of open-ended problem solving in regular academic subjects to develop students' creativity: An analytical review. Turkish Journal of Giftedness and Education, 1 (1), 1-43. doi:10.1.1.685.5815\&rep=rep1\&type=pdf 
Brandwein, F. (1992). Science talent: The play of exemplar and paradigm in the science education of science prone young. Science Education, 76(6), 121-139.

Brandwein, P. (1995). Science talent in the young expressed within ecologies of achievement (RBDM 9510). Storrs, CT: The National Research Center on the Gifted and Talented, University of Connecticut.

Cai, J., \& Lester, F. (2010). Why is teaching with problem solving important to student learning? Retrieved from http://www.nctm.org/uploadedFiles/Research_News_and_Advocacy/ Research/Clips_and_Briefs/Research_brief_14_-_Problem_Solving.pdf

Chamberlin, S. A. (2010). Mathematical problems that optimize learning for academically advanced students in grades K-6. Journal of Advanced Academics, 22(1), 52-76. doi.org/10.1177/1932202X1002200103

Cheng, W. Y., Lam, S. F., \& Chan, C. Y. (2008). When high achievers and low achievers work in the same group: The roles of group heterogeneity and processes in project-based learning. British Journal of Educational Psychology, 78(2), 205-221.

Coxbill, E., Chamberlin, S. A., \& Weatherford, J. (2013). Using model-eliciting activities as a tool to identify and develop mathematically creative students. Journal for the Education of the Gifted, 36(2), 176-197. doi:10.1177/0162353213480433

Feng, A. X., VanTassel-Baska, J., Quek, C., Bai, W., \& O'Neill, B. (2005). A longitudinal assessment of gifted students' learning using the integrated curriculum model (ICM): Impacts and perceptions of the William and Mary language arts and science curriculum. Roeper Review, 27(2), 78-83. doi:10.1080/02783190509554294

Finkelstein, N., Hanson, T., Huang, C. W., Hirschman, B., \& Huang, M. (2010). Effects of problem-based economics on high school economics instruction. (NCEE 2010-4110). 
Washington, DC: U.S. Department of Education, Institute of Education Sciences, National Center for Education Evaluation and Regional Assistance.

Freeman, E. (1994). The politics of stakeholder theory: Some future directions. Business Ethics Quarterly 4(4), 409-421. doi:10.2307/3857340

Gallagher, S, A. (1997). Problem-based learning: Where did it come from, what does it do, and where is it going. Journal for Education of the Gifted, 20, 332-362. doi:10.1177/016235329702000402

Gallagher, S. A. \& Gallagher, J. J. (2013). Using Problem-based Learning to Explore Unseen Academic Potential. Interdisciplinary Journal of Problem-based Learning, 7G(1). Available at: http://dx.doi.org/10.7771/1541-5015.1322

Gallagher, S. A., \& Horak, A. (2011). Somewhat like Sisyphus: Systematic implementation of problem based learning (PBL). Gifted Education International, 27(3), 247-262. doi: $10.1177 / 026142941102700303$

Gallagher, S. A., Stepien, W. J., \& Rosenthal, H. (1992). The effects of problem-based learning on problem solving. Gifted Child Quarterly, 36(4), 195-200. DOI: 1177/001698629203600405

Gardner, H. (1992). Assessment in context: The alternative to standardized testing. In B. Gifford \& M. O'Connor (Eds.), Changing assessment: Alternative views of aptitude, achievement, and instruction. (pp. 77-120). Boston, MA: Kluver. doi:10.1007/978-94011-2968-8_4

Gardner, H. (1983) Frames of mind: The theory of multiple intelligences. NY: Basic Books.

Gardner, H. (1999) Intelligences reframed: Multiple intelligences for the 21 st century. NY: Basic Books. 
Gavin, M. K., Casa, T. M., Adelson, J. L., Carroll, S. R., \& Sheffield, L. J. (2009). The impact of advanced curriculum on the achievement of mathematically promising elementary students. Gifted Child Quarterly, 53(3), 188-202. doi:10.1177/0016986209334964

Gomez-Arizaga, M. P., Bahar, A. K., Maker, C. J., Zimmerman, R., Pease, R. (2015). How does science occur in the classroom? Students' perceptions of science instruction during the implementation of the REAPS model. Eurasia Journal of Mathematics, Science \& Technology Education, 12(3), 431-455. doi:10.12973/Eurasia.2016.1209a

Herreid, C., Schiller, N., \& Herreid, K. (2012). Science stories: Using case studies to teach critical thinking. Arlington, VA: NSTA Press.

Hiemster, D. \& Van Yperen, N. W. (2015). The effects of strength-based versus deficit-based self-regulated learning strategies on students' effort. Motivation and Emotion, 39(5), 656668. doi:10.1007/s11031-015-9488-8

Hockett, J. A. (2009). Curriculum for highly able learners that conforms to general education and gifted education quality indicators. Journal for the Education of the Gifted, 32(3), 3 94-440. doi:10.4219/jeg-2009-857

Howley, A., Pendarvis, E., \& Gholson, M. (2005). How talented students in a rural school district experience school mathematics. Journal for the Education of the Gifted, 29(2), 123-160. doi:10.1177/016235320502900202

Hsu, Y.-S, Lin, L.-F, Wu, D.-Y., Lee, D.-Y., \& Hwang, F-K. (2012). A novice-expert study of modeling skills and knowledge structures about air quality. Journal of Science Education and Technology, (21), 588-606. doi: 10.1007/s10956-011-9349-5

Jo, S. \& Maker, C. J. (2011). The effect of the DISCOVER curriculum model on mathematical knowledge and creativity. Asia-Pacific Journal of Gifted and Talented, 3(1), 1-17. 
Johnson, D. A. (2011). Adapting mathematics curricula for high-ability learners. In VanTasselBaska, J., \& Little, C. A. (Eds.), Content-based curriculum for high-ability learners. (2nd ed., pp. 151-186). Waco TX: Prufrock Press.

Kelly, Melissa. (2020, February 5). Wait Time and Education. Retrieved from https://www.thoughtco.com/importance-of-wait-time-8405

Lee, S. Y., Olszewski-Kubilius, P., \& Peternel, G. (2009). Follow-up with students after 6 years of participation in project EXCITE. Gifted Child Quarterly, 53(2), 137-156. doi:10.1177/0016986208330562

Leikin, R. (2010). Teaching the mathematically gifted. Gifted Education International, 27(2), 161-175. doi:10.1177/026142941002700206

Levy, H. M. (2008). Meeting the needs of all students through differentiated instruction: Helping every child reach and exceed standards. Journal of Educational Strategies, 81 (4), 161-164. doi:10.3200/TCHS.81.4.161-164

Maker, C. J. (1993). Creativity, intelligence, and problem-solving: A definition and design for cross-cultural research and measurement related to giftedness. Gifted Education International, 9, 68-77. doi:10.1177/026142949300900202

Maker, C. J. (1996). Identification of gifted minority students: A national problem, needed changes and a promising solution. Gifted Child Quarterly, 40(1), 41-50. doi:10.1177/001698629604000106

Maker, C. J. (2004). Creativity and multiple intelligences: The DISCOVER project and research. In Lau, S., Hui, N.N. A., Ng, Y. C. G. Creativity: When East Meets West. (341 392) Singapore: World Scientific Publishing Co. Pte. Ltd. 
Maker, C. J. (2005). The DISCOVER Project: Improving Assessment and Curriculum for Diverse Gifted Learners. Senior Scholars Series Monograph. Storrs, CT: National Research Center on the Gifted and Talented.

Maker, C. J. (2013). Model-building: A practical way to develop creativity in gifted students in regular classroom settings. Inspire: The Gifted Education Magazine for Educators. 9, 1014 (English); 15-19 (Chinese).

Maker, C. J. (2016). Recognizing and developing spiritual abilities through real-life problem solving. Gifted Education International, 32(3), 271-306. doi:10.1177/0261429415602574

Maker, C. J. (2019). Identifying Exceptional Talent in Science, Engineering, Mathematics Increasing Diversity and Assessing Creative Problem Solving. Manuscript submitted for publication.

Maker, C. J., Alhusaini, A. A., Pease, R., Zimmerman, R., \& Alamiri, F. Y. (2015a). Developing creativity, talents, and interests across the lifespan: Centers for creativity and innovation. Turkish Journal of Giftedness and Education, 5(2), 83-109.

Maker, C. J., Alhusaini, A. A., Zimmerman, R. H., Pease, R., Schiever, S. W., \& Whitford, D. K. (2014). Recommendations for Developing Curricula for Creativity and Innovation in Saudi Special Schools for Gifted Students: Report of Phase I. Submitted to King Abdulaziz University and the Saudi Arabia Ministry of Education, Riyadh, Saudi Arabia. Maker, C. J. \& Anuruthwong, U. (2003). The miracle of learning: The prism model. Proceedings of the 15th Biennial World Conference of the World Council for Gifted and Talented Students. Adelaide, Australia: World Council for Gifted and Talented Students. 
Maker, C. J., Jo, S., \& Muammar, O. (2008). Development of Creativity: The influence of traditional and non-traditional pedagogy. Learning and Individual Differences, 18, 402417. doi:10.1016/j.lindif.2008.03.003

Maker, C. J. \& King, M.A. (1996). Nurturing Giftedness in Young Children. Reston, VA: Council for Exceptional Children.

Maker, C. J., Muammar, O., Serino, L., Kuang, C. C., Mohamed, A., \& Sak, U. (2006). The DISCOVER curriculum model: Nurturing and enhancing creativity in all children. Korean Educational Development Institute (KEDI) Journal of Educational Policy, 3(2), 99-121.

Maker, C. J., \& Nielson, A. B. (1995). Teaching models in education of the gifted. Austin, TX: Pro-ed.

Maker, C. J. \& Pease, R. (in press). Developing literacy through strength-based education: The Discovering Intellectual Strengths and Capabilities while Observing Varied Ethnic Responses (DISCOVER) approach. Creative and Gifted Journal.

Maker, C. J. Rogers, J. A. \& Nielson, A. B. (1996). Multiple intelligences, problem solving, and diversity in the general classroom. Journal for the Education of the Gifted, 19(4), 437460. doi:10.1177/016235329601900404

Maker, C. J. \& Schiever, S. W. (2010). Curriculum development and teaching strategies for gifted learners. (3rd Ed.). Austin, TX: Pro-Ed.

Maker, C. J. \& Wearne, M. (in press, available online 2019). Engaging gifted students in solving real problems creatively: Implementing the Real Engagement in Active Problem Solving (REAPS) teaching/learning model in Australasian and Pacific Rim contexts. In S. R. 
Smith (Ed.). International Handbook of Giftedness \& Talent Development in the AsiaPacific, Singapore: Springer International Handbooks of Education

Maker, C. J. \& Zimmerman, R.H. (2008). Problem Solving in a Complex World: Integrating DISCOVER, TASC, and PBL in a Teacher Education Project. Gifted Education International. 24(2/3), 160-178. doi:10.1177/026142940802400305

Maker, C. J., Zimmerman, R, Alhusaini, A. \& Pease, R. (2015b). Real Engagement in Active Problem Solving (REAPS): An evidence-based model that meets content, process, product, and learning environment principles recommended for gifted students. APEX. The New Zealand Journal of Gifted Education, 19(1), Retrieved from www.Gifted children.org AZ/apex.

Maker, C. J., Zimmerman, R. H., Gomez-Arizaga, M.P., Pease, R. \& Burke, E. M. (2015c). Developing real-life problem solving: Integrating the DISCOVER problem matrix, problem based learning, and thinking actively in a social context. In Vidergor, H. E. \& Harris, C. R. (Eds.) Applied Practice for Educators of Gifted and Able Learners. (131168) London: Routledge. doi:10.1007/9789463000048_009

Maker, C. J., Zimmerman, R. H., Pease, R., \& Jo, S. (2014). Cultivating Diverse Talent in Science, Technology, Engineering, and Mathematics (STEM): Assessment Report. Department of Disability and Psychoeducational Studies, University of Arizona, Tucson, AZ.

Mann, E. L. (2006). Creativity: The essence of mathematics. Journal for the Education of the Gifted, 30(2), 236-260. doi:10.4219/jeg-2006-264 
Mann, E. L., Mann, R. L., Strutz, M. L., Duncan, D., \& Yoon, S. Y. (2011). Integrating engineering into K-6 curriculum developing talent in the STEM disciplines. Journal of Advanced Academics, 22(4), 639-658. doi:10.1177/1932202X11415007

Matsko, V., \& Thomas, J. (2014). The problem is the solution creating original problems in gifted mathematics classes. Journal for the Education of the Gifted, 37(2), 153-170. doi:10.1177/0162353214529043

Mergendoller, J. R., Maxwell, N. L., \& Bellisimo, Y. (2006). The effectiveness of problem-based instruction: A comparative study of instructional methods and student characteristics. Interdisciplinary Journal of Problem-based Learning, 1(2), 49-69. doi:10.7771/15415015.1026

Mioduser, D., \& Betzer, N. (2008). The contribution of Project-based-learning to high-achievers' acquisition of technological knowledge and skills. International Journal of Technology and Design Education, 18(1), 59-77. doi:10.1007/s10798-006-9010-4

Moore, T. J. (2008). Model-eliciting activities: A case-based approach for getting students interested in material science and engineering. Journal of Materials Education, 30(5-6), 295-310. doi:10.7771/1541-5015.1026

National Association for Gifted Children. (2010). NAGC pre-K-grade 12 gifted programming standards. A blueprint for quality gifted education programs. Washington, DC: Author National Science Board [NSB]. (2010). Preparing the Next Generation of STEM Innovators: Identifying and Developing our Nation's Human Capital. Arlington, VA: National Science Foundation.

Okoda, A. \& Shum, B.S., (2008). Evidence-based dialogue maps as a research tool to investigate 
the quality of school pupils' scientific argumentation. International Journal of Research \& Method in Education (31)3, 291-316. doi:10.1080/17437270802417184

Perrone, K. M., Wright, S. L., Ksiazak, T. M., Crane, A. L., \& Vannatter, A. (2010). Looking back on lessons learned: Gifted adults reflect on their experiences in advanced classes. Roeper Review, 32(2), 127-139. doi:10.1080/02783191003587918

Reinoso, J. (2011). Real-life problem solving: Examining the effects of alcohol within a community on the Navajo nation. Gifted Education International, 27(3), 288-299. doi:10.1177/026142941102700306

Renzulli, J. S., \& Renzulli, S. R. (2010). The schoolwide enrichment model: A focus on student strengths and interests. Gifted Education International, 26(2-3), 140-156. doi:10.1177/026142941002600303

Riley, T., Webber, M., \& Sylva, K. (2017). Real engagement in active problem solving for Māori boys: A case study in a New Zealand secondary school. Gifted and Talented International. 32(2), 75-86. doi:10.1080/15332276.2018.1522240

Rowe, M. B. (1972). Wait-time and rewards as instructional variables, their influence in language, logic, and fate control. Paper presented at the National Association for Research in Science Teaching, Chicago, IL, ED 061103.

Sarouphim, K.M., \& Maker, C. J. (2010). Ethnic and Gender Differences in Identifying Gifted Students: A Multi-Cultural Analysis. International Education, Vol. 39(2), 42-56.

Sierre-Fernandez, J., \& Perales-Palacios, F. (2003). The effects of instruction with computer simulation as a research tool on open-ended problem-solving in a Spanish classroom of 16 year-olds. Computers in Mathematics and Science Teaching, 22(2), 119-140.

Retrieved from https://www.learntechlib.org/primary/p/14454/. 
Sternberg, R. J. (1999). Intelligence as developing expertise. Contemporary Educational Psychology, 24, 359-375. doi:10.1006/ceps.1998.0998

Tal, R. T., \& Miedijensky, S. (2005). A model of alternative embedded assessment in a pull-out enrichment program for the gifted. Gifted Education International, 20(2), 166-186. doi:10.1177/026142940502000208

Tomlinson, C.A. (2013). Differentiated instruction. In Callahan, C. M., \& Plucker, J. (Eds.) Critical issues and practices in gifted education: What the research says. (pp. 197-210) Sourcebooks, Inc.

VanTassel-Baska, J. (2014). Performance-based assessment: The road to authentic learning for the gifted. Gifted Child Today, 37, 41-47. doi:10.1177/1076217513509618

Van Tassel-Baska, J. (2002). Planning effective curriculum experiences for gifted learners. Understanding Our Gifted, 15(1), 6-8.

VanTassel-Baska, J., \& Little, C. A. (Eds.) (2011). Content-based curriculum for high-ability learners. 2nd ed. Waco, TX: Prufrock Press Inc.

VanTassel-Baska, J., \& Wood, S. (2010). The integrated curriculum model (ICM). Learning and individual differences, 20(4), 345-357 doi:10.1016/j.lindif.2009.12.006

Wallace, B. (2008). The early seedbed of the growth of TASC: Thinking Actively in a Social Context. Gifted Education International. 24(2-3), 139-155. doi:10.1177/026142940802400303

Wallace, B., Maker, C. J., Cave, D., \& Chandler, S. (2004). Thinking skills and problemsolving: An inclusive approach. London: David Fulton Publishers.

Wallach, M.A. (1976). Tests tell us little about talent. American Scientist, 64(1), 57-63.

Webber, M., Riley, T., Sylva, K., \& Scobie-Jennings, E. (2018). The Ruamano project: Raising 
expectations, realising community aspirations and recognising gifted potential in Māori boys. The Australian Journal of Indigenous Education, 1-12. doi:10.1017/jie.2018.16

Wu, E. H. (2013). The path leading to differentiation an interview with Carol Tomlinson. Journal of Advanced Academics, 24(2), 125-133. doi:10.1177/1932202X13483472

Wu, I-C., Pease, R., \& Maker, C.J. (2015). Students' perceptions of Real Engagement in Active Problem Solving. Gifted and Talented International. 30(1-2), 106-121. doi:10.1080/15332276.2015.1137462

Wu, I-C., Pease, R., \& Maker, C. J. (2019). Students' perceptions of a special program for developing exceptional talent in STEM. Journal of Advanced Academics, 30(4) 474-499. doi:10.1177/1932202X19864690

Zimmerman, R., Maker, C. J., Gomez-Arizaga, M.P., Pease, R. (2011). The use of concept maps in facilitating problem solving in earth science. Gifted education international 27(3): 274-287. doi:10.1177/026142941102700305 


\section{Table 1}

Questions for Developing a Case Study

\begin{tabular}{lll}
\hline The Beginning & The Middle & The End \\
\hline Where does the problem or & How is the situation & How will you leave the status \\
conflict occur? & developing? & of the problem or conflict?
\end{tabular}

What is the context, the

What events or factors

What are the major players

history of the situation?

transpire that contribute to the

doing, thinking and feeling?

conflict or problem?

What facts do your

Are they under pressure

participants need to

What are the major characters

(time, money, outsiders such

understand the problem or doing?

as the government pushing

conflict?

for resolution) to solve the

Are there new characters

problem or resolve the

Who are the major

coming into play? Who are

conflict?

characters?

they? What connection do

they have to the situation and

Do you want to assign your

What is their relationship to

to the other characters?

participants specific roles

each other?

from within the story? Or do

Are new facts available?

you want to assign them an

"outside" role, such as a

What is happening to the

mediator called in to resolve

relationships between the

the conflict or problem? 
characters? Tempers rising?

Positions getting harder? How much guidance do you want to give you participants

How has the problem or in how they should go about conflict changed as a result of resolving the problem or what is happening now? conflict?

From Maker, C. J., Zimmerman, R. H., Gomez-Arizaga, M.P., Pease, R. \& Burke, E. M. (2015). Developing reallife problem solving: Integrating the DISCOVER problem matrix, problem based learning, and thinking actively in a social context. In Vidergor, H. E. \& Harris, C. R. (Eds.) Applied Practice for Educators of Gifted and Able Learners. (131-168) London: Routledge). 
Table 2

Sample Evaluation of Implementation

\begin{tabular}{|c|c|c|c|c|c|c|}
\hline \multicolumn{7}{|c|}{ Evaluation of Implementation (Example from Stakeholder Group: Environmental Protections) } \\
\hline \multirow[b]{2}{*}{$\begin{array}{l}\text { Models, Flow } \\
\text { Charts, Dramas, } \\
\text { Parts of the } \\
\text { Solution }\end{array}$} & \multicolumn{6}{|c|}{ Criteria: List them below for reference purposes } \\
\hline & $\begin{array}{l}\text { Is it } \\
\text { original } \\
\text { or } \\
\text { creative? }\end{array}$ & Teamwork? & $\begin{array}{l}\text { Details of } \\
\text { thinking? }\end{array}$ & $\begin{array}{l}\text { Feasible or } \\
\text { possible? }\end{array}$ & $\begin{array}{l}\text { Negative } \\
\text { impact of } \\
\text { problem? }\end{array}$ & $\begin{array}{l}\text { Horizontal } \\
\text { Totals }\end{array}$ \\
\hline Improve law making & 2 & 2 & 2 & 2 & 2 & 10 \\
\hline Improve standards & 1 & 2 & 2 & 2 & 1 & 8 \\
\hline $\begin{array}{l}\text { Incentives such as } \\
\text { money for } \\
\text { technologies }\end{array}$ & 2 & 2 & 2 & 2 & 1 & 9 \\
\hline $\begin{array}{l}\text { Public } \\
\text { communications }\end{array}$ & 1 & 2 & 2 & 2 & 2 & 9 \\
\hline Training & 0 & 1 & 2 & 2 & 2 & 7 \\
\hline Improve data quality & 2 & 2 & 2 & 2 & 1 & 9 \\
\hline Improve equipment & 1 & 1 & 2 & 2 & 2 & 8 \\
\hline $\begin{array}{l}\text { Establish a platform } \\
\text { for Feedback }\end{array}$ & 0 & 1 & 2 & 1 & 1 & 5 \\
\hline Vertical Totals & 9 & 13 & 16 & 15 & 12 & \\
\hline Averages & $\mathbf{1 . 3 7}$ & 1.75 & 2 & 1.87 & 1.5 & \\
\hline \multicolumn{7}{|c|}{$\begin{array}{l}\text { Scoring for each idea } \\
0=\text { poor; unknown } \\
1=\text { average, possibly } \\
2 \text { = excellent, definitely }\end{array}$} \\
\hline
\end{tabular}




\section{Table 3}

Sample of Commissioner or panel of experts' evaluation form

\begin{tabular}{|c|c|c|}
\hline $\begin{array}{l}\text { Commissioners or panel of experts will evaluate your presentations on the } \\
\text { following criteria: }\end{array}$ & YES & NO \\
\hline Are the recommendations presented clearly? & & \\
\hline Is the presentation persuasive? & & \\
\hline Is the presentation engaging and interesting? & & \\
\hline Does the presentation include data to support the group's recommendations? & & \\
\hline Are the supporting data presented effectively? & & \\
\hline Are the sources sited? & & \\
\hline Are the plastic problems addressed in detail? & & \\
\hline Are the ecosystem health problems addressed in detail? & & \\
\hline Does the group address the varied and specific problems of plastic pollution? & & \\
\hline Is the presentation based on scientific data and knowledge? & & \\
\hline $\begin{array}{l}\text { Do the presenters demonstrate that they understand the potential sources of plastic } \\
\text { pollution? }\end{array}$ & & \\
\hline $\begin{array}{l}\text { Do the presenters demonstrate that they know what kinds of human activities cause } \\
\text { these types of problems? }\end{array}$ & & \\
\hline $\begin{array}{l}\text { Do the presenters demonstrate that they understand what must be done to reduce the } \\
\text { impact of plastics? }\end{array}$ & & \\
\hline Is the plan presented by the group realistic? & & \\
\hline Does it represent the point of view of the stakeholder? & & \\
\hline
\end{tabular}




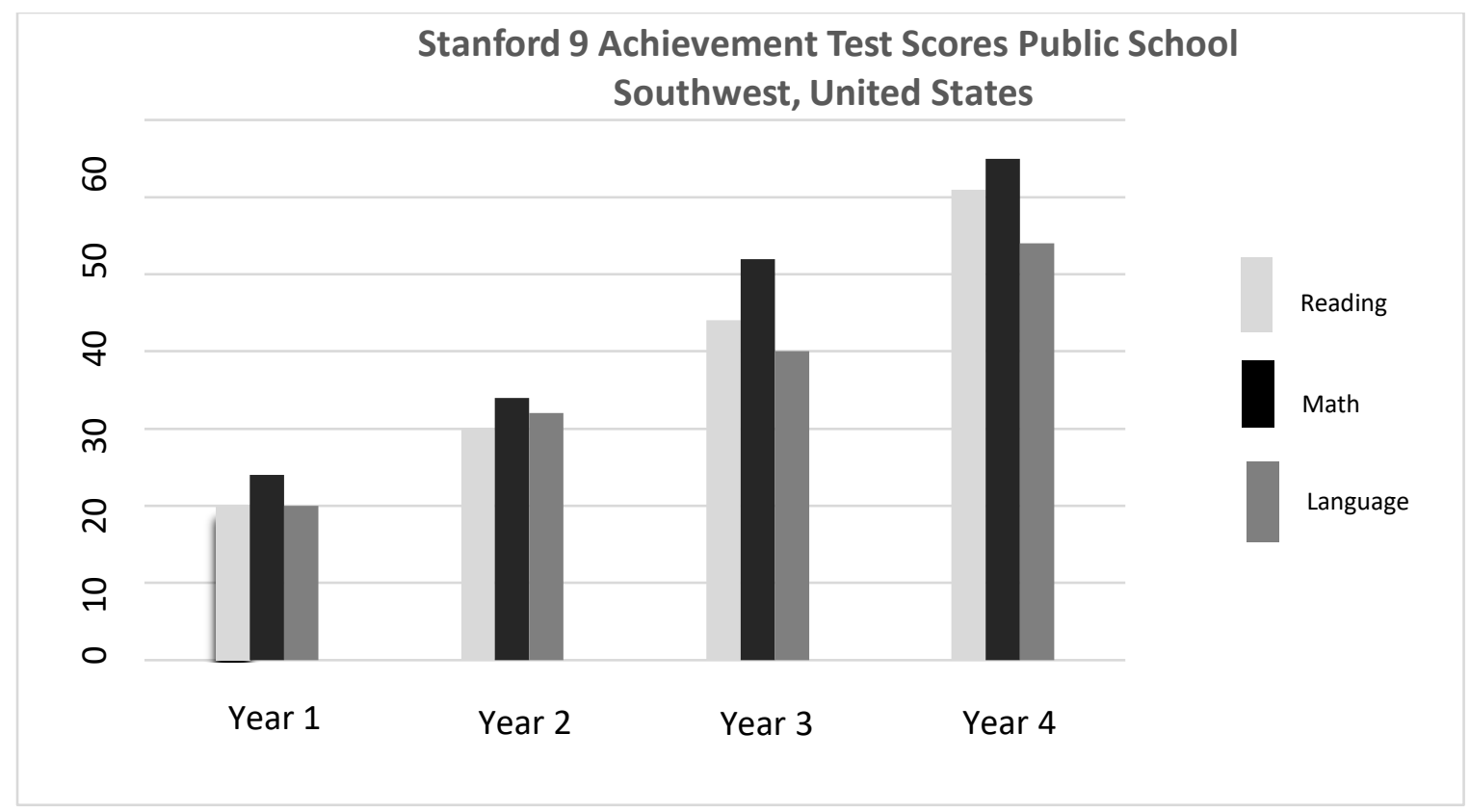

Figure 1. DISCOVER site results. 

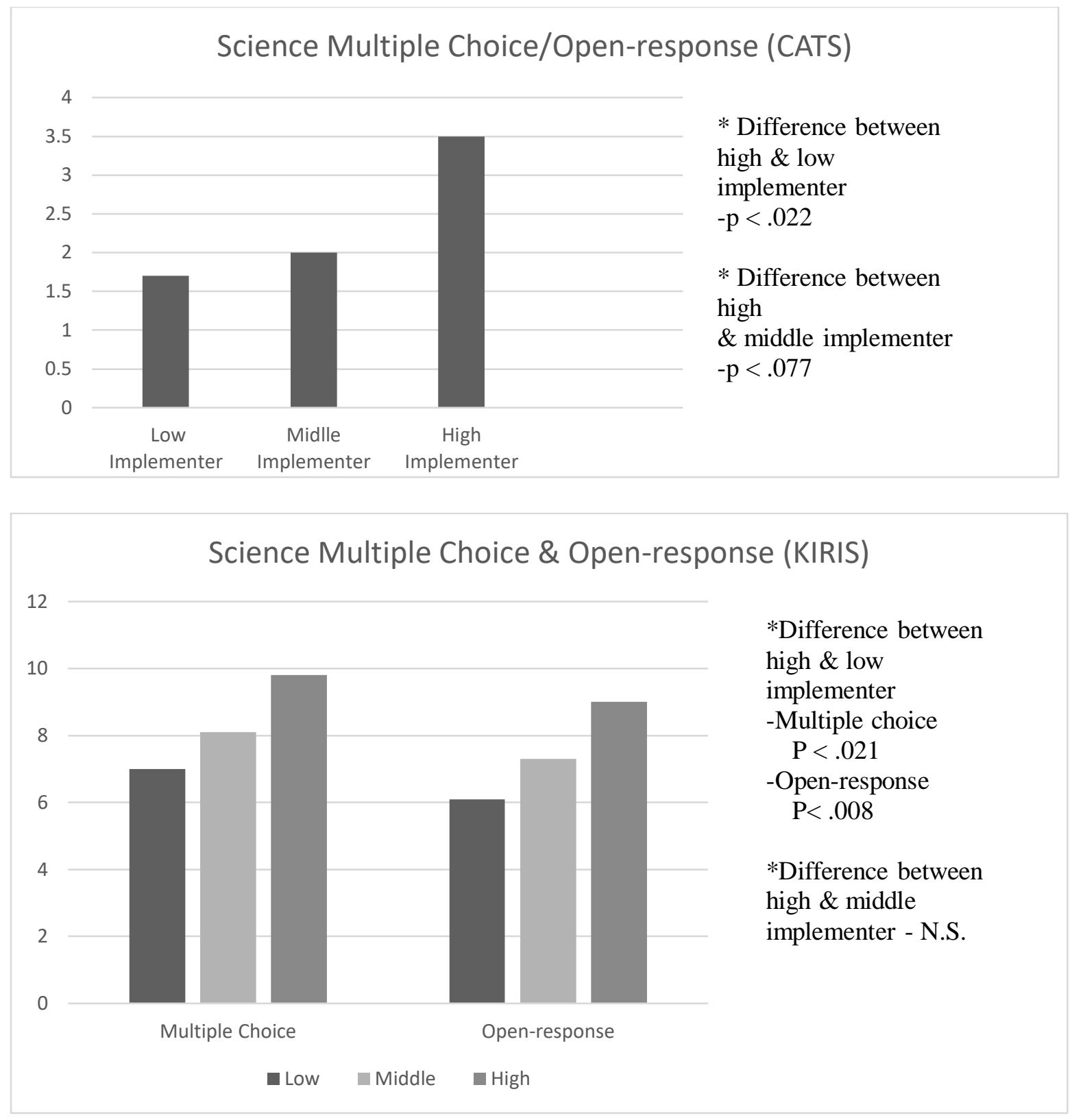

Figure 2. Differences between high, middle, and low implementers in science achievement scores 


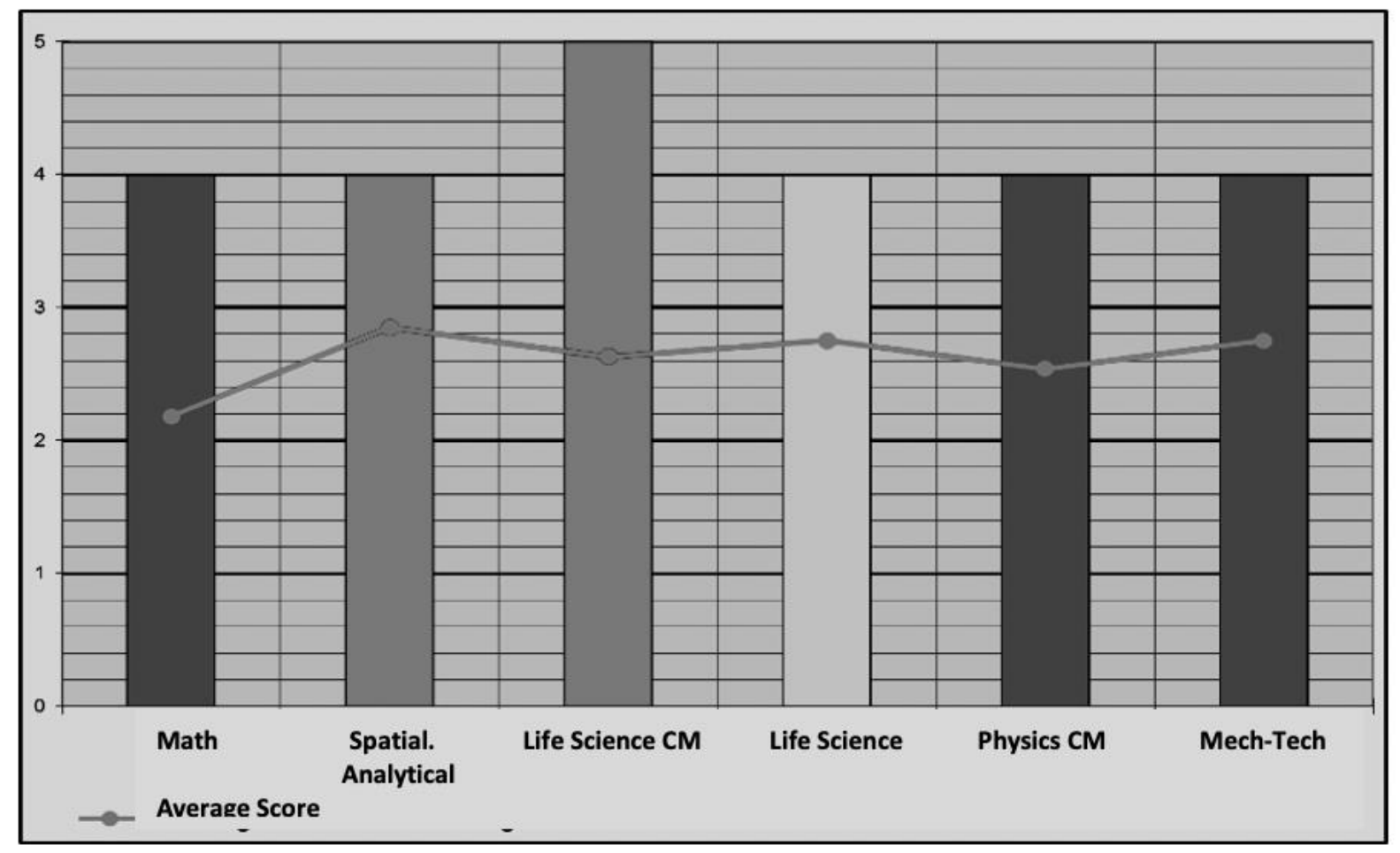

Student A

Figure 3. Student A profile of assessment results 


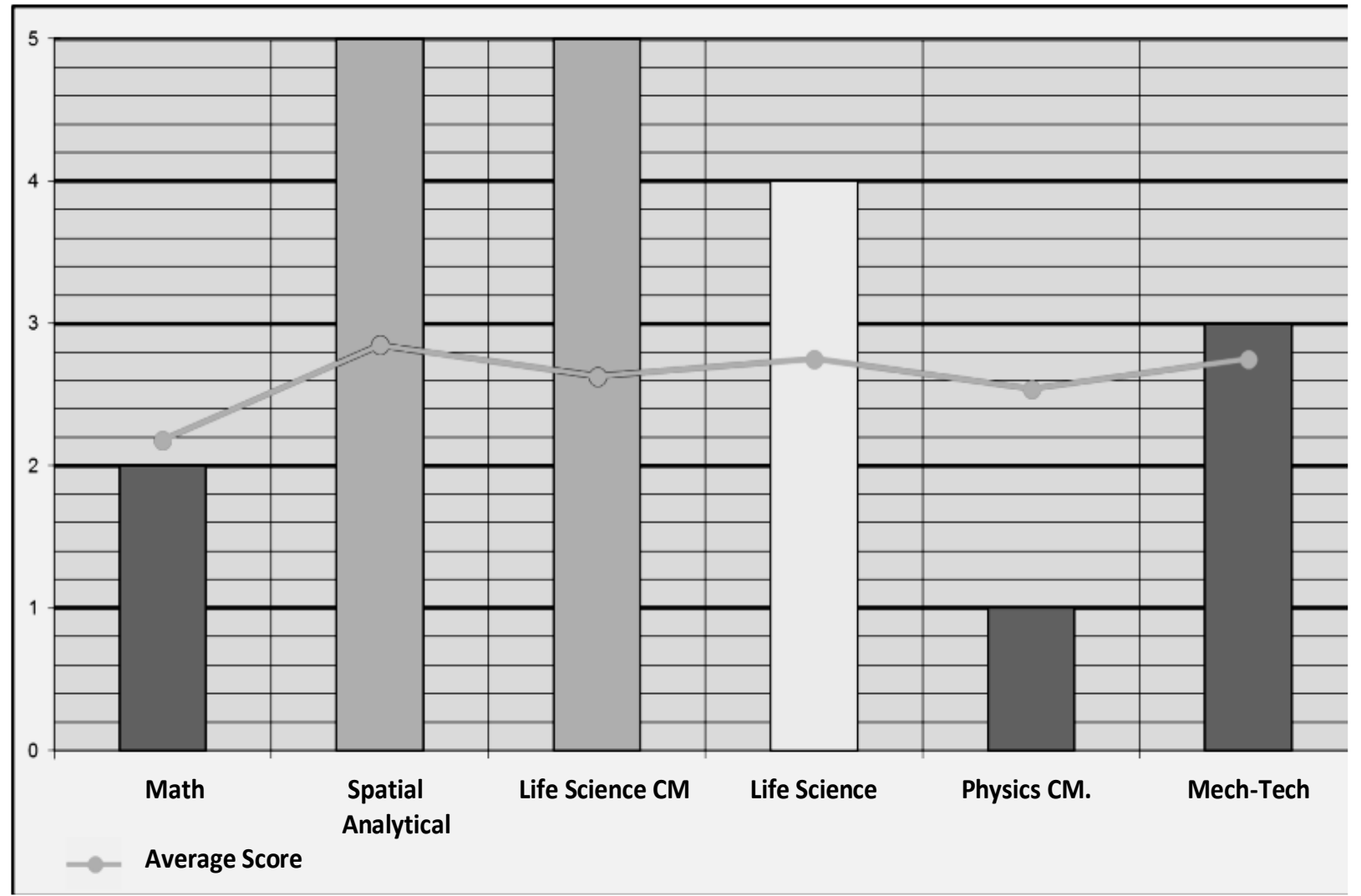

Student E

Figure 4. Student E profile of assessment results 


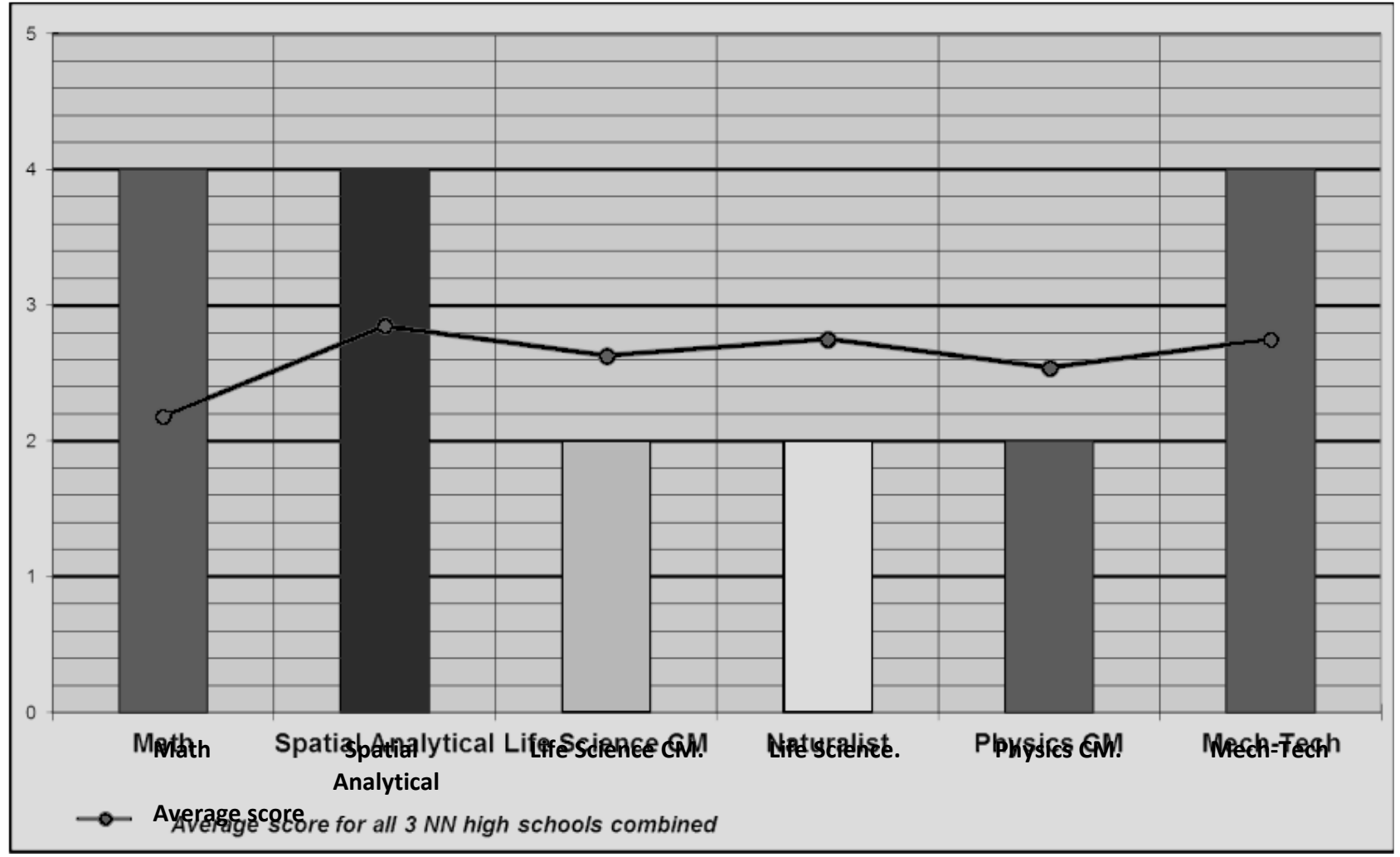

\section{Student P}

Figure 5. Student $P$ profile of assessment results 


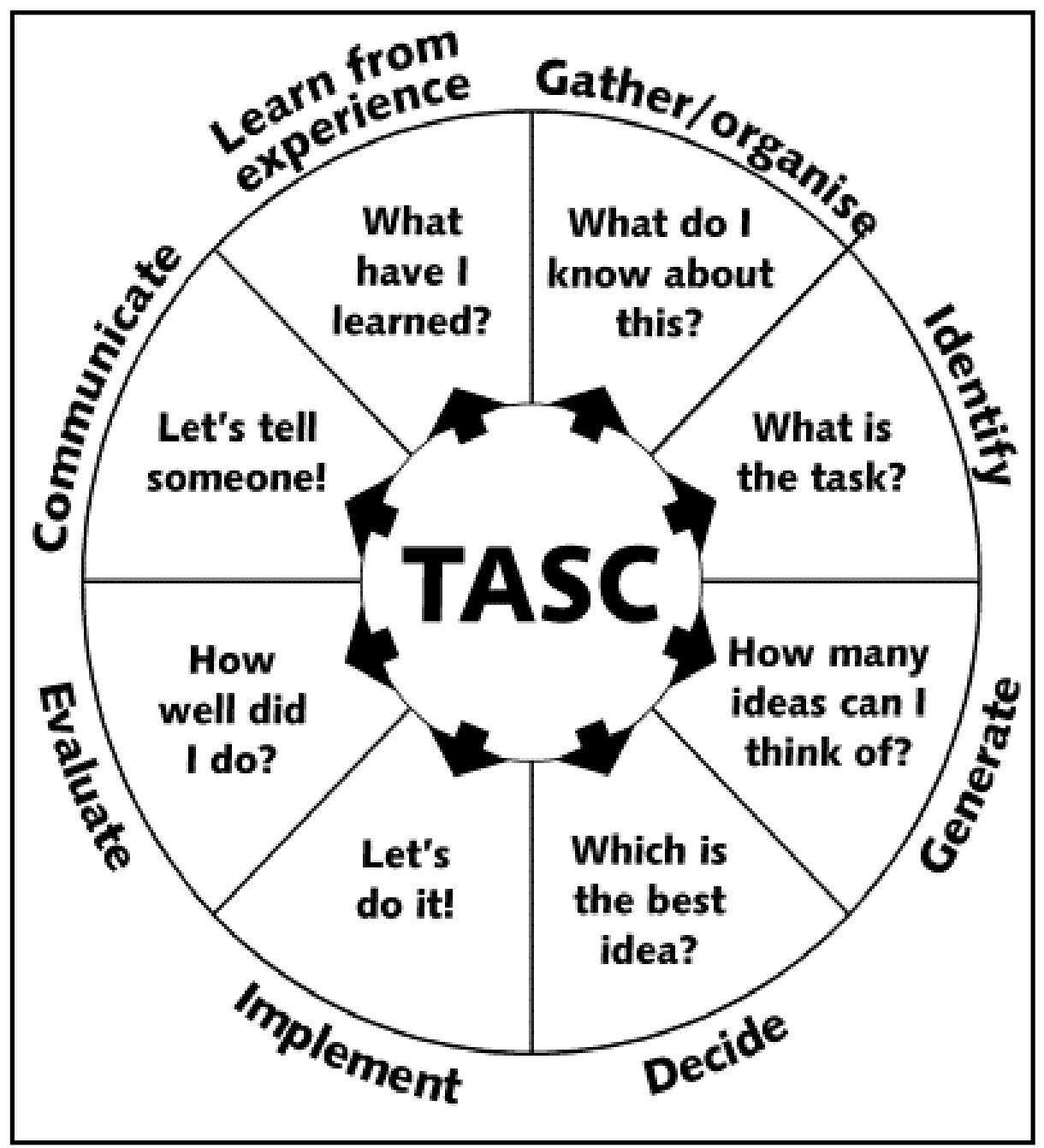

Figure 6. Thinking Actively in a Social Context (TASC) Wheel

The figure was reprinted from Wallace B. (2003). Using history to develop thinking skills at key stage 2. London: David Fulton Publishers. 